UISA/TM-GSS- 207222

\title{
Photochemistry of Triton's atmosphere and ionosphere
}

\author{
Vladimir A. Krasnopolsky' \\ National Research Council/NASA Goddard Space Flight Center, Greenbelt, Maryland \\ Dale P. Cruikshank ' \\ Astrophysics Branch, NASA Ames Research Center, Moffett Field, California '
}

\begin{abstract}
The photochemistry of 32 neutral and 21 ion species in Triton's atmosphere is considered. Parent species $\mathrm{N}_{2}, \mathrm{CH}_{4}$, and $\mathrm{CO}$ (with a mixing ratio of $3 \times 10^{-4}$ in our basic model) sublime from the ice with rates of 40,208 , and $0.3 \mathrm{~g} / \mathrm{cm}^{2} / \mathrm{b} . y$., respectively. Chemistry below $50 \mathrm{~km}$ is driven mostly by photolysis of methane by the solar and interstellar medium Lyman-alpha photons, producing hydrocarbons $\mathrm{C}_{2} \mathrm{H}_{4}, \mathrm{C}_{2} \mathrm{H}_{6}$, and $\mathrm{C}_{2} \mathrm{H}_{2}$ which form haze particles with precipitation rates of 135,28 , and $1.3 \mathrm{~g} / \mathrm{cm}^{2} / \mathrm{b}$.y., respectively. Some processes are discussed which increase the production of HCN (by an order of magnitude to a value of $29 \mathrm{~g} / \mathrm{cm}^{2} / \mathrm{b}$.y.) and involve indirect photolysis of $\mathrm{N}_{2}$ by neutrals. Reanalysis of the measured methane profiles gives an eddy diffusion coefficient $K=4 \times 10^{3} \mathrm{~cm}^{2} / \mathrm{s}$ above the tropopause and a more accurate methane number density near the surface, $(3.1 \pm 0.8) \times 10^{11} \mathrm{~cm}^{-3}$. Chemistry above $200 \mathrm{~km}$ is driven by the solar EUV radiation $(\lambda<1000 \AA)$ and by precipitation of magnetospheric electrons with a total energy input of $10^{8} \mathrm{~W}$ (based on thermal balance calculations). The most abundant photochemical species are $\mathrm{N}, \mathrm{H}_{2}, \mathrm{H}, \mathrm{O}$, and $\mathrm{C}$. They escape with the total rates of $7.7 \times 10^{24} \mathrm{~s}^{-1}, 4.5 \times 10^{25} \mathrm{~s}^{-1}, 2.4 \times 10^{25} \mathrm{~s}^{-1}, 4.4 \times 10^{22} \mathrm{~s}^{-1}$, and $1.1 \times 10^{24} \mathrm{~s}^{-1}$, respectively. Atomic species are transported to a region of $50-200 \mathrm{~km}$ and drive the chemistry there. Ionospheric chemistry explains the formation of an $E$ region at $150-240 \mathrm{~km}$ with $\mathrm{HCO}^{+}$as a major ion, and of an $F$ region above $240 \mathrm{~km}$ with a peak at $320 \mathrm{~km}$ and $\mathrm{C}^{+}$as a major ion. The ionosphere above $500 \mathrm{~km}$ consists of almost equal densities of $\mathrm{C}^{+}$and $\mathrm{N}^{+}$ions. The model profiles agree with the measured atomic nitrogen and electron density profiles. A number of other models with varying rate coefficients of some reactions, differing properties of the haze particles (chemically passive or active), etc., were developed. These models show that there are four basic unknown values which have strong impacts on the composition and structure of the atmosphere and ionosphere. These values and their plausible ranges are the $\mathrm{CO}$ mixing ratio $f_{\mathrm{CO}}=10^{-4}-10^{-3}$, the magnetospheric electron energy input $(1 \pm 0.5) \times 10^{8} \mathrm{~W}$, the rate coefficient of charge-exchange reaction $\mathrm{N}_{2}^{+}+\mathrm{C} k$ $=10^{-11}-10^{-10} \mathrm{~cm}^{3} / \mathrm{s}$, and the ion escape velocity $v_{i} \approx 150 \mathrm{~cm} / \mathrm{s}$.
\end{abstract}

\section{Introduction}

There are few basic experimental facts about the atmosphere of Triton. Ground-based spectroscopy shows the presence of $\mathrm{N}_{2}, \mathrm{CH}_{4}, \mathrm{CO}$, and $\mathrm{CO}_{2}$ in the surface ice with relative fractions $1: 5 \times 10^{-4}: 10^{-3}: 10^{-3}$ [Cruikshank et al., 1984, 1993; Cruikshank and Apt, 1984], and these species, except $\mathrm{CO}_{2}$, should exist in the atmosphere. Voyager radio occultations [Tyler et al., 1989; Yelle et al., 1991] measured the atmospheric pressure $p=13.5 \pm 1 \mathrm{dyn} / \mathrm{cm}^{2}$ and the mean temperature of $40 \pm 5 \mathrm{~K}$ in the lowest $50 \mathrm{~km}$. The ionosphere with a peak electron density of $(3.5 \pm 1) \times 10^{4} \mathrm{~cm}^{-3}$ at $340 \mathrm{~km}$ was observed as well. Voyager Ultraviolet Spectrometer (UVS) solar occultation spectroscopy [Broadfoot et al.," 1989; Krasnopolsky et al., 1993] measured the $\mathrm{N}_{2}$ density profile between 450 and $750 \mathrm{~km}$, which can be described by

Copyright 1995 by the American Geophysical Union.

Paper number 95JE01904.

0148-0227/95/95JE-01904\$05.00 the $\mathrm{N}_{2}$ density at $575 \mathrm{~km},\left[\mathrm{~N}_{2}\right]=(4 \pm 0.4) \times 10^{8} \mathrm{~cm}^{-3}$, and the isothermal temperature $T=102 \pm 3 \mathrm{~K}$. The distribution of atomic nitrogen observed by the same instrument corresponds to diffusive equilibrium above $300 \mathrm{~km}$ with $[\mathrm{N}]=(1 \pm$ $0.25) \times 10^{8} \mathrm{~cm}^{-3}$ at $400 \mathrm{~km}$ and $T=100 \pm 7 \mathrm{~K}$, and $[\mathrm{N}]=(5$ $\pm 2.5) \times 10^{8} \mathrm{~cm}^{-3}$ at $200 \mathrm{~km}$. The total escape rate of atomic nitrogen is equal to $(1 \pm 0.3) \times 10^{25} \mathrm{~s}^{-1}$ [Krasnopolsky et al., 1993]. Methane and haze profiles have been deduced from the Voyager UVS solar occultations [Herbert and Sandel, 19911. Both nitrogen and methane are nearly saturated at the surface temperature of $38 \pm 3 \mathrm{~K}$ measured by the Voyager IR spectrometer [Conrath et al., 1989] and of $38 \pm 1 \mathrm{~K}$ determined from the profile of the $2.148 \mu \mathrm{m}$ band of solid nitrogen [Tryka et al., 1994]. Haze and clouds seen in images of Triton have been studied by Pollack et al. [1990] and Rages and Pollack [1992]. Study of both UVS and television observations of haze yields various properties of the haze as functions of height up to $30 \mathrm{~km}$ [Krasnopolsky et al., 1992; Krasnopolsky, 1993b], of which the specific surface is the most important for our problem. Dark plumes 
(chimneys), which are vertical up to $8 \mathrm{~km}$ and which become horizontal at this height, indicate the position of the tropopause [Yelle et al., 1991]. High-energy electrons found in Neptune's magnetosphere in the vicinity of Triton's orbit [Krimigis et al., 1989] are thought to be a source of ionization and heating of Triton's atmosphere.

These basic facts may be used for more detailed analyses of the atmosphere. In spite of some important differences between thermal balance calculations by Stevens et al. [1992] and Krasnopolsky et al. [1993], both papers showed that the mean magnetospheric electron energy input $P=10^{8} \mathrm{~W}$ was required to reproduce the measured densities and temperatures. Among the differences was an upper limit on the $\mathrm{CO}$ mole fraction (mixing ratio) $\mathrm{f}_{\mathrm{CO}} \leq 2 \times 10^{-4}$ given by Stevens et al. [1992] based on cooling by the $\mathrm{CO}$ rotational lines, while Krasnopolsky et al. [1993] showed that a CO fraction up to $10^{-2}$ is compatible with the UVS observations. Later Strobel and Summers [1995] came to the conclusion that a model with $P=1.4 \times 10^{8} \mathrm{~W}$ and $f_{\mathrm{co}}=2.5 \times 10^{-4}$ provided the best fit to the measurements and claimed $f_{\mathrm{CO}} \leq 3 \times 10^{-4}$ as an improved upper limit. These revisions were given without explanations, and the new limit was too close to their preferred value. Besides, they argued that Table 2 in Krasnopolsky et al. [1993] suggested $f_{\mathrm{co}} \leq 10^{-3}$. However, that table was given for fixed values of the magnetospheric electron energy input and the heating efficiency. A larger variety of models was shown in Table 4 of the same paper, and we do not see reasons to reconsider their results. Despite all of the differences among the models of Stevens et al. [1992], Krasnopolsky et al. [1993], and Strobel and Summers [1995], the observational constraints made their profiles of temperature and density rather close to each other, and the background $\mathrm{N}_{2}$ atmosphere may now be considered as known with good accuracy. For example, typical differences between the profiles of Krasnopolsky et al. [1993] and of Strobel and Summers [1995] are 1-2 K in temperature and $15-20 \%$ in density.

Few photochemistry papers have appeared since the Voyager encounter. Strobel et al. [1990a] considered methane chemistry below $100 \mathrm{~km}$, which results in formation of the higher hydrocarbons precipitating to the surface, and of molecular and atomic hydrogen, which escape. They suggested that condensation of the higher hydrocarbons forms the haze observed by Voyager. (Krasnopolsky et al. [1992] use this idea as an initial assumption for modeling the haze and its UV and visible extinctions and reflectivities.) The first ionospheric models were calculated by Majeed et al. [1990] and Yung and Lyons [1990], who showed that there is a strong coupling between the neutral (lower and upper) atmosphere and the ionosphere. Therefore later models by Summers and Strobel [1991] and Lyons et al. [1992] treated both neutral and ionospheric composition. Lyons et al. [1992] pointed out the importance of neutral and ionized atomic carbon on Triton. The low ionization potential of carbon makes carbon ions stable in the upper atmosphere, which mostly consists of molecular and atomic nitrogen and hydrogen. Solar radiation is the only source of ionization in the model of Lyons et al. [1992], and a very long lifetime of $\mathrm{C}^{+}$permits a fit to the ionospheric observations. A chargeexchange reaction between $\mathrm{N}_{2}^{+}$and $\mathrm{C}$ was a source of $\mathrm{C}^{+}$, and the required rate coefficient was very large, $10^{-9} \mathrm{~cm}^{3} / \mathrm{s}$.

The discovery of $\mathrm{CO}$ in the surface ice [Cruikshank et al., 1993] stimulated further studies of Triton's photochemistry.
Three preprints appeared in 1993 on this subject: J. R. Lyons et al. (Photochemistry of the atmosphere and ionosphere of triton, submitted to Icarus, 1993; hereafter referred to as LYA93), V. A. Krasnopolsky and D. P. Cruikshank (unpublished data, 1993), and Strobel and Summers [1995] (hereafter referred to as SS95. The presence of CO makes the photochemistry more complex and interesting due to the appearance of oxygen species. Furthermore, carbon monoxide, like methane, is a source of carbon atoms, and it makes it possible to model the ionosphere profile with a more realistic rate coefficient of the $\mathrm{N}_{2}{ }^{+}+\mathrm{C}$ reaction. The conditions of saturation of $\mathrm{CO}$ on Triton correspond to the $\mathrm{CO}$ mixing ratio of $7 \%$. Then the application of Raoult's law to the $\mathrm{CO}$ mixing ratio in the ice, $10^{-3}$, yields its mixing ratio of $0.07 \times 10^{-3}=7 \times 10^{-5}$ in the atmosphere. However, the atmosphere-ice system may not be in local equilibrium, as is the case for methane, for which the atmospheric abundance exceeds that predicted by Raoult's law by 3 orders of magnitude. That is why measurements of the $\mathrm{CO}$ abundance in the atmosphere are badly needed.

LYA93 will be a basic reference in our study here. They assumed the $\mathrm{CO}$ mixing ratio of $10^{-4}$ in the atmosphere and succeeded in reproducing the measured peak electron density by the solar model (without precipitation of magnetospheric electrons) and with the $\mathrm{N}_{2}^{+}+\mathrm{C}$ reaction rate coefficient $\left(k_{84}\right.$ in our notation) of $10^{-10} \mathrm{~cm}^{3} / \mathrm{s}$. SS95 is a review chapter which does not discuss many important details of their model (e. g., profiles of only five species from their latest model are shown, and other profiles given in the paper represent the corrected version of Summers and Strobel [1991]). Their model is based on the magnetospheric electron energy input of $1.4 \times 10^{8} \mathrm{~W}$, the $\mathrm{CO}$ mixing ratio $f_{\mathrm{CO}}=2.5 \times 10^{-4}$, and $k_{84}=$ $10^{-11} \mathrm{~cm}^{3} / \mathrm{s}$. We will compare our models with SS95 where possible.

As with LYA93 and SS95, the objective of this paper is a self-consistent model of the atmosphere of Triton including its ionosphere. However, our models differ in some important details from those papers, and this difference is what has stimulated this work.

\section{General Ideas of Photochemistry of the Atmosphere and Ionosphere of Triton}

General ideas of the photochemistry of the atmosphere and ionosphere of Triton were discussed in previous papers, and we descibe them very briefly to give more attention to specific problems. Solar EUV radiation shortward of $1000 \AA$ and precipitating magnetospheric electrons ionize and dissociate $\mathrm{N}_{2}$ and produce $\mathrm{N}, \mathrm{N}_{2}^{+}$, and $\mathrm{N}^{+}$with an $\mathrm{N}_{2}^{+} / \mathrm{N}^{+}$ production ratio of 5 (this ratio is almost the same for EUV photon and low-energy electron impacts). This occurs mostly at $200-500 \mathrm{~km}$. Solar radiation in the range $1000-1400 \AA$ (Lyman-alpha $1216-\AA$ photons constitute $80 \%$ of this radiation) and the Lyman-alpha interstellar background with an intensity of 340 Rayleigh (SS95) dissociate methane in the lowest $40 \mathrm{~km}$ to produce $\mathrm{CH}_{3}, \mathrm{CH}, \mathrm{H}$, and $\mathrm{H}_{2}$. Some part of the methane is rebuilt from $\mathrm{CH}_{3}$ and $\mathrm{H}$, but further destruction of $\mathrm{CH}_{4}$ in a reaction with $\mathrm{CH}$ results in a total yield of the methane photolysis $\gamma \approx 1$ (0.6 in Strobel et al. [1990a] and 1.1 in our models). Reactions of $\mathrm{CH}_{3}$ and $\mathrm{CH}$ form more complex hydrocarbons; $\mathrm{C}_{2} \mathrm{H}_{4}, \mathrm{C}_{2} \mathrm{H}_{6}$, and $\mathrm{C}_{2} \mathrm{H}_{2}$ are the most abundant. The saturation densities of these hydrocarbons are of the order of a few molecules per cubic 
centimeter at $40 \mathrm{~K}$, and therefore these species condense and form a haze, which was observed up to $30 \mathrm{~km}$ by the Voyager $2 \mathrm{TV}$ and UVS instruments. The ratio $\mathrm{C}: \mathrm{H}=1: 4$ in $\mathrm{CH}_{4}$ and $\approx 1: 2$ in the photochemically formed hydrocarbons, and therefore $2 \gamma$ hydrogen atoms are released per photon due to the hydrocarbon chemistry. These hydrogen atoms constitute an upward hydrogen flow, which escapes and which is equal to the $1000-1400 \AA$ photon flux multiplied by $2 \gamma$, i.e. $5 \times 10^{8} \mathrm{~cm}^{-2} \mathrm{~s}^{-1}$ and $1.15 \times 10^{26} \mathrm{~s}^{-1}$ from the whole satellite. The $\mathrm{H}_{2}: \mathrm{H}$ ratio is determined in this flow by chemical processes in the atmosphere and ionosphere, however, the total hydrogen flow is rather stable and should not depend on a chosen chemical model. This flow is diffusion limited, so the $\left(2 \mathrm{H}_{2}+\mathrm{H}\right)$ mixing ratio should be rather constant with height in the atmosphere and equal to $f$ $\approx \Phi H / b \approx 2 \times 10^{-4}$. Here $\Phi$ is the flow, $H \approx 15 \mathrm{~km}$ is the scale height, $b=D n=1.88 \times 10^{17} T^{0.82} \mathrm{~cm}^{-1} \mathrm{~s}^{-1}$ [Chamberlain and Hunten, 1987], and $D$ is the diffusion coefficient of $\mathrm{H}_{2}$ in $\mathrm{N}_{2}$. The loss of methane by photolysis is compensated by its transport by eddy and molecular diffusion, and the measured methane profiles [Herbert and Sandel, 1991] are used to determine the eddy diffusion coefficient.

The neutral atmosphere at ionospheric heights, i.e., above $200 \mathrm{~km}$, consists of molecular and atomic nitrogen and hydrogen and $\mathrm{CO}$, which is rather inert below $200 \mathrm{~km}$. The primary $\mathrm{N}_{2}^{+}$and $\mathrm{N}^{+}$ions react with $\mathrm{H}_{2}$ to form $\mathrm{N}_{2} \mathrm{H}^{+}$and $\mathrm{NH}^{+}$and recombine. Some part of the primary ions exchange their charge with $\mathrm{CO}$ and form $\mathrm{CO}^{+}$. Recombination of $\mathrm{CO}^{+}$ is the main source of $\mathrm{C}$ and $\mathrm{O}$ atoms in the atmosphere. Small fractions of the $N, C$, and $O$ atoms escape, and downward flows of these atoms interact with each other and with other components of the atmosphere below $150 \mathrm{~km}$. The primary result of this interaction is recombination to $\mathrm{N}_{2}$ and $\mathrm{CO}$, though some $\mathrm{HCN}$, other nitriles, $\mathrm{H}_{2} \mathrm{CO}$, and $\mathrm{CO}_{2}$ form and condense.

The lifetime of $\mathrm{N}_{2}^{+}$is rather short due charge-exchange and recombination processes, and its density should be far smaller than the measured peak electron density (3.5 \pm 1) $\times 10^{4} \mathrm{~cm}^{-3}$. Radiative recombination of $\mathrm{N}^{+}$is much slower than dissociative recombination of $\mathrm{N}_{2}^{+}$and other molecular ions. However, $\mathrm{N}^{+}$can be lost in the chargeexchange reactions with $\mathrm{H}_{2}$ and $\mathrm{CO}$. Therefore the first ionospheric models [Majeed et al., 1990; Yung and Lyons, 1990] explored an idea that the ion column production rate could exceed the $\mathrm{H}_{2}$ production in the lower atmosphere, and the excess $\mathrm{N}^{+}$ions should recombine radiatively, forming a dense ionosphere. Later, Summers and Strobel [1991] reduced the requirement to the ion production rate by enhanced formation of $\mathrm{H}^{+}$in charge-exchange of $\mathrm{N}_{2}^{+}$with $\mathrm{H}$. $\mathrm{H}^{+}$vanished in reactions with hydrocarbon and nitriles. Later measurements gave only a rather low upper limit to a rate coefficient of this reaction, and $\mathrm{H}^{+}$densities are strongly reduced in the case of $\mathrm{CO}$ (see below). In the presence of $\mathrm{CO}$ and hence $\mathrm{C}$, the charge-exchange reaction between $\mathrm{N}_{2}^{+}$ and $\mathrm{C}$ forms $\mathrm{C}^{+}$ions. These ions have a very long chemical lifetime because they can either recombine radiatively or react with $\mathrm{HCN}, \mathrm{CH}_{4}$, and the other hydrocarbons, which are very scarce at the ionospheric heights.

These are the basic ideas of Triton's photochemistry. The experimental $\mathrm{N}_{2}$ densities and thermal balance calculations provide the background $\mathrm{N}_{2}$ atmosphere. The measured $\mathrm{CH}_{4}$ densities are used as the boundary condition for this parent species and allow us to determine the eddy diffusion coeffi- cient. The measured electron density profile and the atomic nitrogen profile are used to check a validity of a model.

\section{Reactions and Their Rate Coefficients}

One of the problems in modeling Triton's photochemistry is the lack of measurements of reaction rate coefficients at temperatures typical of Triton's atmosphere. The situation is fairly good for ionospheric reactions which typically exhibit small temperature dependences. The temperature behaviors have been measured for some basic ion reactions (see references in work by Anicich [1993]). Our knowledge is less satisfactory for neutral reactions in the upper atmosphere where $T=100 \mathrm{~K}$, and is very poor for reactions in the lower atmosphere with $T \approx 40-50 \mathrm{~K}$.

Some reactions proceed via an energy barrier $E$ (in Kelvins), and their rate coefficients are given in the Arrhenius form $k=A e^{-E / T}$. Temperature behavior of a reaction without the energy barrier is determined mostly by a potential energy function of interacting molecules and may be given as $k=A(300 / T)^{a}$. Both types may combine to form $k$ $=A(300 / T)^{\alpha x} \mathrm{e}^{-E / T}$, which is used, for example, in the RRKM approximation. Our reference guide for neutral reactions is Chemical Kinetics Database [Mallard et al., 1994]. The detailed physics is unknown in many experimental studies of reaction rate coefficients, and one of the above functions is sometimes arbitrarily chosen to represent the experimental results. Typically this choice is not important in a measured temperature range, but it is crucial for extrapolation to Triton's temperatures. Therefore we transform rate coefficients of all three-body association reactions, given in the Arrhenius form, to the power form, because these reactions proceed typically without an energy barrier. For example, a rate coefficient of

$$
\mathrm{O}+\mathrm{O}+\mathrm{N}_{2} \rightarrow \mathrm{O}_{2}+\mathrm{N}_{2}
$$

was measured by Campbell and Gray [1973] and given as $k$ $=9.5 \times 10^{-34} e^{485 / \mathrm{T}} \mathrm{cm}^{6} / \mathrm{s}$. This corresponds to $k=5 \times 10^{-33}$ $(300 / T)^{2} \mathrm{~cm}^{6} / \mathrm{s}$ in the temperature range of their measurements, 196-300 K, and this form is widely used in photochemistry. Furthermore, we are cautious in extrapolations of rate coefficients given with a negative activation energy $E$, and either the power form or constant values will be used.

The number of compounds consisting of $\mathrm{N}, \mathrm{H}, \mathrm{C}$, and $\mathrm{O}$ atoms is so huge that we try to reduce both the number of compounds and their reactions in our model to a reasonable minimum. Shown in Table I are 75 reactions of 31 neutral species, and in Table 2, 63 reactions of 20 ions. We show in these tables the main reactions which determine balances of the parent species $\left(\mathrm{N}_{2}, \mathrm{CH}_{4}, \mathrm{CO}\right)$, the principal photochemical products $\left(\mathrm{N}, \mathrm{H}, \mathrm{H}_{2}, \mathrm{C}, \mathrm{O}, \mathrm{C}_{2} \mathrm{H}_{4}, \mathrm{HCN}, \mathrm{C}_{2} \mathrm{H}_{6}, \mathrm{C}_{2} \mathrm{H}_{2}\right)$, and the principal ions $\left(\mathrm{C}^{+}, \mathrm{N}^{+}, \mathrm{N}_{2}^{+}, \mathrm{N}_{2} \mathrm{H}^{+}, \mathrm{CO}^{+}\right.$, and $\left.\mathrm{HCO}^{+}\right)$. Though hydrocarbons and $\mathrm{HCN}$ are very scarce at ionospheric heights, we take special care to describe in detail their reactions with ions because their densities, even of the order of $1000 \mathrm{~cm}^{-3}$, may be important for $\mathrm{C}^{+}$. To minimize the number of species and their reactions, we do not use reactions which do not change production and loss of the basic species. For example, the net effect of

$$
\begin{aligned}
& \mathrm{HCO}^{+}+\mathrm{HCN} \rightarrow \mathrm{HCNH}^{+}+\mathrm{CO} \\
& \frac{\mathrm{HCNH}^{+}+e \rightarrow \mathrm{HCN}+\mathrm{H}}{\text { net } \mathrm{HCO}^{+}+e \rightarrow \mathrm{CO}+\mathrm{H}}
\end{aligned}
$$

adds almost nothing to dissociative recombination of $\mathrm{HCO}^{+}$. 
Table 1. Neutral Reactions in Triton's Atmosphere, Their Rate Coefficients and Column Rates

\begin{tabular}{|c|c|c|c|c|}
\hline & Reaction & Rate Coefficient & Reference & Column Rate \\
\hline$\overline{1 a}$ & $\mathrm{CH}_{4}+h \mathrm{v} \rightarrow \mathrm{CH}_{3}+\mathrm{H}$ & $\gamma=0.49 \quad 7.9 \times 10^{-9}$ & Mordaunt et al. [1993] & $1.10+8^{7}$ \\
\hline lb & $\rightarrow \mathrm{CH}+\mathrm{H}+\mathrm{H}_{2}$ & 0.506 & & $1.14+8$ \\
\hline Ic & $\rightarrow \mathrm{C}+\mathrm{H}_{2}+\mathrm{H}_{2}$ & 0.004 & Braun et al. $|1969|$ & $9.00+5$ \\
\hline 2 & $\mathrm{C}_{2} \mathrm{H}_{2}+h v \rightarrow \mathrm{C}_{2} \tilde{\mathrm{H}}+\mathrm{H}$ & $9 \times 10^{43}$ & Okabe [1983| & $2.24+4$ \\
\hline 3 & 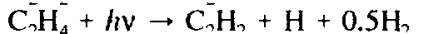 & $3 \times 10^{-8}$ & Yung et al. [1984] & $5.60+5$ \\
\hline $4 a$ & $\mathrm{C}_{2} \mathrm{H}_{6}+h v \rightarrow \mathrm{C}_{2} \mathrm{H}_{4}+\mathrm{H}+0.5 \mathrm{H}_{2}$ & $4 \times 10^{-9}$ & Yung et al. [1984] & $1.35+4$ \\
\hline $4 b$ & $\rightarrow \mathrm{C}_{2} \mathrm{H}_{2}+2 \mathrm{H}_{2}$ & $2 \times 10^{4}$ & Yung et al. [1984] & $6.77+3$ \\
\hline 5 & $\mathrm{HCN}+h v \rightarrow \breve{H}+\mathrm{CN}$ & $2 \times 10^{-8}$ & Yung et al. [1984] & $2.80+5$ \\
\hline 6 & $\mathrm{HCN}_{2}+h v \rightarrow \mathrm{CH}+\mathrm{N}_{2}$ & $3 \times 10^{-7}$ & see text & $1.26+6$ \\
\hline 7 & $\mathrm{~N}_{2}+h v \rightarrow \mathrm{N}+\mathrm{N}$ & - & Zipf and McLaughlin [1978] & $1.77+7$ \\
\hline 8 & $\mathrm{CO}+h v \rightarrow \mathrm{C}+\mathrm{O}$ & - & see text & $3.80+5$ \\
\hline 9 & $\mathrm{~N}_{2}+e \rightarrow \mathrm{N}+\mathrm{N}+e$ & - & Fox and Victor [1988] & $5.04+7$ \\
\hline 10 & $\mathrm{CO}+e \rightarrow \mathrm{C}+\mathrm{O}+e$ & - & similar to $N_{2}$ & $1.64+3$ \\
\hline 11 & $\mathrm{~N}+\mathrm{N}+\mathrm{M} \rightarrow \mathrm{N}_{2}+\mathrm{M}$ & $4 \times 10^{-33}(300 / T)^{2}$ & Campbell and Thrush [1967] & $1.67+7$ \\
\hline 12 & $\mathrm{H}+\mathrm{H}+\mathrm{M} \rightarrow \mathrm{H}_{2}+\mathrm{M}$ & $9 \times 10^{-33}(300 / T)^{1.3}$ & Tsang and Hampson [1986] & $6.85+7$ \\
\hline 13 & $\mathrm{C}+\mathrm{C}+\mathrm{M} \rightarrow \mathrm{C}_{2}+\mathrm{M}$ & $5.5 \times 10^{31}(300 / T)^{1.6}$ & Slack [1976] & $6.23+4$ \\
\hline 14 & $\mathrm{O}+\mathrm{O}+\mathrm{M} \rightarrow \mathrm{O}_{2}^{-}+\mathrm{M}$ & $5 \times 10^{-33}(300 / T)^{2}$ & Campiell and Gray [1973] & $1.54+5$ \\
\hline 15 & $\mathrm{C}+\mathrm{O}+\mathrm{M} \rightarrow \mathrm{CO}+\mathrm{M}$ & $5 \times 10^{-33}(300 / T)^{2}$ & assumed & $7.56+3$ \\
\hline 16 & $\mathrm{~N}+\mathrm{H}+\mathrm{M} \rightarrow \mathrm{NH}+\mathrm{M}$ & $5 \times 10^{-32}(300 / T)$ & Brown [1973] & $3.60+7$ \\
\hline 17 & $\mathrm{~N}+\mathrm{C}+\mathrm{M} \rightarrow \mathrm{CN}+\mathrm{M}$ & $10^{-32}(300 / T)$ & Kley et al.[1974] & $3.42+4$ \\
\hline 18 & $\mathrm{~N}+\mathrm{O}+\mathrm{M} \rightarrow \mathrm{NO}+\mathrm{M}$ & $10^{-32}(300 / T)^{0.65}$ & Campbell and Gray [1973] & $2.87+5$ \\
\hline 19 & $\mathrm{H}+\mathrm{O}+\mathrm{M} \rightarrow \mathrm{OH}+\mathrm{M}$ & $4.4 \times 10^{-32}(300 / T)$ & Tsang and Hampson [1986] & $2.04+5$ \\
\hline 20 & $\mathrm{H}+\mathrm{CH}_{3}+\mathrm{M} \rightarrow \mathrm{CH}_{4}+\mathrm{M}$ & $6 \times 10^{-29}(300 / T)^{1.8}$ & Baulch et al. [1992] & $7.18+7$ \\
\hline 21 & $\mathrm{H}_{2}+\mathrm{C}+\mathrm{M} \rightarrow \mathrm{CH}_{2}+\mathrm{M}$ & $1.4 \times 10^{31}(300 / T)$ & Husain and Young [1975] & $2.91+5$ \\
\hline 22 & $\mathrm{H}_{2}+\mathrm{CH}+\mathrm{M} \rightarrow \mathrm{CH}_{3}+\mathrm{M}$ & $6 \times 10^{-30}(300 / T)^{2.3}$ & Berman and Lin [1984] & $4.20+5$ \\
\hline 23 & $\mathrm{CH}_{3}+\mathrm{CH}_{3}+\mathrm{M} \rightarrow \mathrm{C}_{2} \mathrm{H}_{6}+\mathrm{M}$ & $10^{-23}$ & Laufer et al. $[1983\}$ & $1.78+7$ \\
\hline 24 & $\mathrm{CH}+\mathrm{N}_{2}+\mathrm{M} \rightarrow \mathrm{HCN}_{2}+\mathrm{M}$ & $2.6 \times 10^{-31}(300 / T)$ & Berman and Lin [1983a] & $2.14+7$ \\
\hline 25 & $\mathrm{C}+\mathrm{N}_{2}+\mathrm{M} \rightarrow \mathrm{CNN}+\mathrm{M}$ & $3 \times 10^{-33}(300 / T)$ & Husain and Kirsch [1971] & $5.05+7$ \\
\hline 26 & $\mathrm{CH}_{4}+\mathrm{CH} \rightarrow \mathrm{C}_{2} \mathrm{H}_{4}+\mathrm{H}$ & $5 \times 10^{-11} \mathrm{e}^{200 / T} ; 10^{-10 *}$ & Bermon and Lin [1983b] & $9.46+7$ \\
\hline $27 \mathbf{a}$ & $\mathrm{CH}_{3}+\mathrm{N} \rightarrow \mathrm{H}_{2} \overline{\mathrm{CN}}+\mathrm{H}$ & $4.3 \times 10^{-10} e^{-420 / T}$ & Marston et al. [1989] & $3.15+5$ \\
\hline $27 b$ & $\rightarrow \mathrm{HCN}+\mathrm{H}_{2}$ & $4 \times 10^{-11} e^{-420 T T}$ & Marston et al. [1989] & $2.94+4$ \\
\hline 28 & $\mathrm{CH}_{3}+\mathrm{O} \rightarrow \mathrm{H}_{2} \mathrm{CO}+\mathrm{H}$ & $1.4 \times 10^{-10}$ & Baulch et al. [1992] & $3.19+6$ \\
\hline 29 & $\mathrm{CH}_{2}+\mathrm{H} \rightarrow \mathrm{CH}+\mathrm{H}_{2}$ & $10^{-10 *}$ & Baulch et al. [1992] & $3.33+6$ \\
\hline 30 & $\mathrm{CH}_{2}+\mathrm{N} \rightarrow \mathrm{HCN}+\stackrel{\mathrm{H}}{2}$ & $5 \times 10^{-11} e^{-250 / T}$ & Yung et al. [1984] & $4.34+4$ \\
\hline 31 & $\mathrm{CH}_{2}+\mathrm{O} \rightarrow \mathrm{CO}+\mathrm{H}_{2}$ & $2 \times 10^{-10}$ & Baulch et al. [1992] & $1.43+6$ \\
\hline 32 & $\mathrm{CH}^{2}+\mathrm{N} \rightarrow \mathrm{CN}+\mathrm{H}^{-}$ & $2 \times 10^{-11}$ & Messing et al. [1981] & $1.91+6$ \\
\hline 33 & $\mathrm{CH}+\mathrm{H} \rightarrow \mathrm{C}+\mathrm{H}_{2}$ & $5 \times 10^{-11}$ & Harding et al. [1993] & $2.82+6$ \\
\hline 34 & $\mathrm{CH}+\mathrm{C} \rightarrow \mathrm{C}_{2}+\mathrm{H}$ & $5 \times 10^{-11}$ & assumed & $2.05+4$ \\
\hline 35 & $\mathrm{CH}+\mathrm{O} \rightarrow \mathrm{CO}+\mathrm{H}$ & $5 \times 10^{-11}$ & Baulch et al. [1992] & $3.27+5$ \\
\hline 36 & $\mathrm{CH}+\mathrm{H}_{2} \mathrm{CO} \rightarrow \mathrm{CH}_{2}+\mathrm{HCO}$ & $10^{-10 *}$ & Baulch et al. [1992] & $2.99+6$ \\
\hline 37 & $\mathrm{NH}+\mathrm{H}^{2} \rightarrow \mathrm{N}+\mathrm{H}_{2}{ }^{-}$ & $5 \times 10^{-11}$ & Morley [1981] & $4.58+7$ \\
\hline 38 & $\mathrm{NH}+\mathrm{N} \rightarrow \mathrm{N}_{2}+\mathrm{H}$ & $5 \times 10^{-11}$ & Miller et al. [1985] & $1.03+7$ \\
\hline 39 & $\mathrm{NH}+\mathrm{C} \rightarrow \mathrm{CN}+\mathrm{H}$ & $5 \times 10^{-11}$ & assumed & $2.37+3$ \\
\hline 40 & $\mathrm{NH}+\mathrm{O} \rightarrow \mathrm{NO}+\mathrm{H}$ & $1.2 \times 10^{-10}$ & Cohen and Westberg [1991] & $4.29+5$ \\
\hline 41 & $\mathrm{CNN}+\mathrm{N} \rightarrow \mathrm{CN}+\mathrm{N}_{2}$ & $2 \times 10^{-11}$ & assumed & $4.13+7$ \\
\hline 42 & $\mathrm{CNN}+\mathrm{H} \rightarrow \mathrm{CH}+\mathrm{N}_{2}$ & $2 \times 10^{-11}$ & assumed & $5.64+6$ \\
\hline 43 & $\mathrm{CNN}+\mathrm{C} \rightarrow \mathrm{C}_{2}+\mathrm{N}_{2}$ & $2 \times 10^{-11}$ & assumed & $2.69+5$ \\
\hline 44 & $\mathrm{CNN}+\mathrm{O} \rightarrow \mathrm{CO}+\mathrm{N}_{2}$ & $2 \times 10^{-11}$ & assumed & $3.35+6$ \\
\hline 45 & $\mathrm{CN}+\mathrm{N} \rightarrow \mathrm{C}+\mathrm{N}_{2}$ & $10^{-10}$ & Whyte and Phillips [1983] & $4.53+7$ \\
\hline 46 & $\mathrm{CN}+\mathrm{O} \rightarrow \mathrm{CO}+\mathrm{N}$ & $1.7 \times 10^{-11}$ & Baulch et al. [1992] & $6.16+5$ \\
\hline 47 & $\mathrm{CN}+\mathrm{C}_{2} \mathrm{H}_{2} \rightarrow \mathrm{HCN}+\mathrm{C}_{2} \mathrm{H}$ & $2.7 \times 10^{-10}(300 / T)^{0.5} e^{-19 / T}$ & Sims et al. [1993] & $6.22+4$ \\
\hline 48 & $\mathrm{CN}+\mathrm{C}_{2} \mathrm{H}_{4} \rightarrow \mathrm{HCN}+\mathrm{C}_{2} \mathrm{H}_{3}$ & $2.5 \times 10^{-10}(T / 300)^{0.7} e^{-28 / T}$ & Sims et al. [1993] & $2.94+4$ \\
\hline 49 & $\mathrm{CN}+\mathrm{C}_{2} \mathrm{H}_{6} \rightarrow \mathrm{HCN}+\mathrm{C}_{2} \mathrm{H}_{5}$ & $2.1 \times 10^{-11}(T / 300)^{0.22} e^{58 / T}$ & Sims et al. [1993] & $3.39+3$ \\
\hline 50 & $\mathrm{CN}+\mathrm{H}_{2} \mathrm{CO} \rightarrow \mathrm{HCN}+\mathrm{HCO}$ & $5 \times 10^{-14} T^{*}$ & Yu et al. [1993] & $2.07+5$ \\
\hline 51 & $\mathrm{C}_{2} \mathrm{H}_{2}+\mathrm{C} \rightarrow \mathrm{C}_{3}+\mathrm{H}_{2}$ & $10^{-11 *}$ & Haider and Husain [1993] & $1.02+6$ \\
\hline 52 & $\mathrm{C}_{2} \mathrm{H}_{4}+\mathrm{C} \rightarrow \mathrm{C}_{2} \mathrm{H}_{2}+\mathrm{CH}_{2}$ & $10^{-11 *}$ & Haider and Husain [1993] & $1.47+6$ \\
\hline 53 & $\mathrm{C}_{2} \mathrm{H}_{6}+\mathrm{C} \rightarrow \mathrm{C}_{2} \mathrm{H}_{4}+\mathrm{CH}_{2}$ & $10^{-11}$ & assumed & $5.80+4$ \\
\hline 54 & $\mathrm{C}_{2} \mathrm{H}_{4}+\mathrm{O} \rightarrow \mathrm{CH}_{3}+\mathrm{HCO}$ & $1.5 \times 10^{-12}(T / 300)^{1.5} e^{-215 / T}$ & Tsang and Hampson [1986] & $1.70+5$ \\
\hline 55 & $\mathrm{~N}+\mathrm{O} \rightarrow \mathrm{NO}+h \mathrm{v}$ & $1.8 \times 10^{-17}(300 / T)^{0.5}$ & Dalgarno et al. [1992] & $4.96+7$ \\
\hline 56 & $\mathrm{~N}+\mathrm{OH} \rightarrow \mathrm{NO}+\mathrm{H}$ & $5 \times 10^{-11}(300 / T)^{0.25}$ & Howard and Smith [1981] & $1.99+5$ \\
\hline 57 & $\mathrm{~N}+\mathrm{NO} \rightarrow \mathrm{N}_{2}+\mathrm{O}$ & $3 \times 10^{-11}$ & Baulch et al. [1992] & $5.06+7$ \\
\hline 58 & $\mathrm{CO}+\mathrm{OH} \rightarrow \mathrm{CO}_{2}+\mathrm{H}$ & $2.6 \times 10^{-13} e^{-76 / T}$ & Frost et al. [1993] & $5.30+3$ \\
\hline 59 & $\mathrm{H}_{2} \mathrm{CN}+\mathrm{N} \rightarrow \mathrm{HCN}+\mathrm{NH}$ & $10^{-10} e^{-200 / T}$ & Marston et al. [1989] & $3.15+5$ \\
\hline 60 & $\mathrm{HCN}_{2}+\mathrm{H} \rightarrow \mathrm{HCN}+\mathrm{NH}$ & $10^{-14}$ & assumed & $2.02+7$ \\
\hline 61 & $\mathrm{O}_{2}+\mathrm{C} \rightarrow \mathrm{CO}+\mathrm{O}$ & $10^{-12 *}$ & Dorthe et al. [1991] & $1.54+5$ \\
\hline 62 & $\mathrm{C}_{2}+\mathrm{O} \rightarrow \mathrm{CO}+\mathrm{C}$ & $10^{-12 *}$ & Fairbairn [1969] & $9.52+4$ \\
\hline 63 & $\mathrm{C}_{2}+\mathrm{N} \rightarrow \mathrm{CN}+\mathrm{C}$ & $10^{-12}$ & assumed & $1.27+6$ \\
\hline 64 & $\mathrm{C}_{3}^{2}+\mathrm{O} \rightarrow \mathrm{CO}+\mathrm{C}_{2}$ & $10^{-12}$ & assumed & $7.09+4$ \\
\hline 65 & $\mathrm{C}_{3}+\mathrm{N} \rightarrow \mathrm{CN}+\mathrm{C}_{2}^{2}$ & $10^{-12}$ & assumed & $9.46+5$ \\
\hline 66 & $\mathrm{C}_{2} \mathrm{H}_{5}+\mathrm{H} \rightarrow \mathrm{CH}_{3}+\mathrm{CH}_{3}$ & $6 \times 10^{-11}$ & Baulch et al. [1992] & $3.39+3$ \\
\hline
\end{tabular}


Table 1. (continued)

\begin{tabular}{lllll}
\hline & Reaction & Rate Coefficient & Reference & Column Rate \\
\hline 67 & $\mathrm{C}_{2} \mathrm{H}_{3}+\mathrm{H} \rightarrow \mathrm{C}_{2} \mathrm{H}_{2}+\mathrm{H}_{2}$ & $2 \times 10^{-11}$ & Baulch et al. [1992] & $2.94+4$ \\
68 & $\mathrm{C}_{2} \mathrm{H}+\mathrm{O} \rightarrow \mathrm{CO}+\mathrm{CH}$ & $1.7 \times 10^{-11}$ & Baulch et al. [1992] & $3.97+3$ \\
69 & $\mathrm{C}_{2} \mathrm{H}+\mathrm{N} \rightarrow \mathrm{CN}+\mathrm{CH}$ & $10^{-11}$ & assumed & $8.05+4$ \\
70 & $\mathrm{C}_{2} \mathrm{H}+\mathrm{CH} \rightarrow \mathrm{C}_{2} \mathrm{H}_{2}+\mathrm{CH}_{3}$ & $3 \times 10^{-12} e^{-250 / T}$ & Tsang and Hampson $[1986]$ & 134 \\
71 & $\mathrm{HCO}+\mathrm{H} \rightarrow \mathrm{CO}+\mathrm{H}_{2}$ & $1.5 \times 10^{-10}$ & Baulch et al. [1992] & $3.19+6$
\end{tabular}

\footnotetext{
Photolysis rate coefficients (in $\mathrm{s}^{-1}$ ) are halves of those on Neptune's orbit for $\lambda>80 \mathrm{~nm}$. Rate coefficients are in $\mathrm{cm}^{3} / \mathrm{s}$ and $\mathrm{cm}^{6} / \mathrm{s}$ for second- and third-order reactions, respectively, and column rates (in $\mathrm{cm}^{-2} \mathrm{~s}^{-1}$ ) are normalized to the surface.

* Values adopted for Triton's conditions.

$1.10+8=1.10 \times 10^{8}$.
}

The same holds for some branches of dissociative recombinations and ion-molecule reactions, e.g.,

$$
\begin{aligned}
& \mathrm{N}_{2}^{+}+\mathrm{O} \rightarrow \mathrm{O}^{+}+\mathrm{N}_{2} \\
& \mathrm{O}^{+}+\mathrm{N}_{2} \rightarrow \mathrm{NO}^{+}+\mathrm{N} \\
& \text { net } \mathrm{N}_{2}^{+}+\mathrm{O} \rightarrow \mathrm{NO}^{+}+\mathrm{N}
\end{aligned}
$$

just repeats the main branch of the $\mathrm{N}_{2}^{+}+\mathrm{O}$ reaction. Before we neglect any species or reaction, we check qualitively for possible effects of this neglection.

Now we begin to discuss some reactions and their rate coefficients which are new or differ substantially from the previous models.

Photolysis of methane was measured recently by Mordaunt et al. [1993] to proceed via

$$
\begin{array}{ll}
\mathrm{CH}_{4}+h v \rightarrow \underset{\mathrm{CH}+\mathrm{H}+\mathrm{H}_{2}}{\mathrm{CH}_{3}+\mathrm{H}} \quad \gamma=0.49 \\
\mathrm{CH}
\end{array}
$$

Previously it was thought that $\mathrm{CH}_{2}$ is the main photolysis product $(\gamma=0.92)$, the rest being CH [e.g., Atreya 1986]. Then reactions

$$
\begin{aligned}
\mathrm{CH}_{2}+\mathrm{H} & \rightarrow \mathrm{CH}+\mathrm{H}_{2} \\
\mathrm{CH}+\mathrm{CH}_{4} & \rightarrow \mathrm{C}_{2} \mathrm{H}_{4}+\mathrm{H}
\end{aligned}
$$

increased the effective photolysis yield to 1.75 , and formation of ethane and acethylene was extremely low [Krasnopolsky et al., 1993]. The high yield of $\mathrm{CH}_{3}$ increases three-body formation of $\mathrm{CH}_{4}$ (reducing the effective photolysis yield to 1.1) and ethane $\mathrm{C}_{2} \mathrm{H}_{6}$.

It was argued by Krasnopolsky et. al [1993] that a rate coefficient of

(R29) $\quad \mathrm{CH}_{2}+\mathrm{H} \rightarrow \mathrm{CH}+\mathrm{H}_{2}$ given as $k_{29}=4.7 \times 10^{-10} \exp (-370 / T) \mathrm{cm}^{3} / \mathrm{s}$ (e.g., LYA93) is not applicable to the low Triton temperatures (it is equal to $5 \times 10^{-14} \mathrm{~cm}^{3} / \mathrm{s}$ at $40 \mathrm{~K}$ ). Baulch et al. [1992] recommend $k_{29}$ $=10^{-10} \exp (300 / T)$, which is too big at low temperatures, and a value of $10^{-10} \mathrm{~cm}^{3} / \mathrm{s}$ will be used. This reaction was of great importance for the old scheme of the methane photolysis which produced much $\mathrm{CH}_{2}$. Its impact is much smaller now.

Current photochemical models presume a formation of $\mathrm{HCN}$ on Triton by (R30) $\mathrm{N}+\mathrm{CH}_{2}$ and (R27) $\mathrm{N}+\mathrm{CH}_{3}$ and ignore the fact that $\mathrm{CH}$ radicals react quickly with $\mathrm{N}_{2}$, the reaction having been observed many times in laboratory (19 references to measurements of this reaction are given by Mallard et al. [1994]). It is thought that this reaction is responsible for dissociating $\mathrm{N}_{2}$ molecules in flames and combustion. However, the reaction to form $\mathrm{HCN}$,

$$
\mathrm{CH}+\mathrm{N}_{2} \rightarrow \mathrm{HCN}+\mathrm{N}
$$

is slightly endothermic and cannot proceed even at room temperature. The most detailed analysis of this process was made by Berman and Lin [1983a], who studied it over a large range of temperatures and pressures. The very complex behavior of the system suggests that the initial process at room and low temperatures is

(R24) $\mathrm{CH}+\mathrm{N}_{2}+\mathrm{M} \rightarrow \mathrm{HCN}_{2}+\mathrm{M} \quad k_{24}=2.8 \times 10^{-31} \mathrm{~cm}^{6} / \mathrm{s}$

This reaction may be followed by a reaction of $\mathrm{HCN}_{2}$, with $\mathrm{CH}$ forming two $\mathrm{HCN}$ molecules with a net energy release of $9.44 \mathrm{eV} . \mathrm{N}$ and $\mathrm{H}$ atoms are much more abundant on Triton than $\mathrm{CH}$, and these are possible candidates to react with $\mathrm{HCN}_{2}$. The rate coefficient $k_{24}$ is rather high; therefore (R24) is spin-allowed and $\mathrm{HCN}_{2}$ has spin 1/2. Then the reaction with $\mathrm{N}^{4} \mathrm{~S}$ ) to form $\mathrm{HCN}+\mathrm{N}_{2}$ is spin forbidden, and (R59) $\mathrm{H}+\mathrm{HCN}_{2}$ is the most probable reaction to proceed. Products other than $\mathrm{HCN}+\mathrm{NH}$ may form, but we ignore other branches and adopt $k_{60}=10^{-14} \mathrm{~cm}^{3} / \mathrm{s}$ for this branch. Berman and $\mathrm{Lin}$ mentioned that the $\mathrm{HC}-\mathrm{N}_{2}$ bond energy is $2 \mathrm{eV}$ and $\mathrm{HCN}_{2}$ dissociates by visible light with a cross section close to that of diazomethane. The latter would have a dissociation rate coefficient of $3 \times 10^{-7} \mathrm{~s}^{-1}$ on Triton (cross section from Okabe [19781). Reactions (R24) and (R60) are the main processes of HCN formation in our model. Berman and Lin [1983a] predict an increase of $k_{24}$ by more than an order of magnitude from $300 \mathrm{~K}$ to $100 \mathrm{~K}$, though they do not preclude the possibility of a small activation energy. The value chosen here reflects these considerations.

The formation of NH in (R60) is mostly followed by (R37) $\mathrm{NH}+\mathrm{H}$. Therefore (R24, 60, and 37) may be considered as a chemical cycle:

$$
\begin{aligned}
& \mathrm{CH}+\mathrm{N}_{2}+\mathrm{M} \rightarrow \mathrm{HCN}_{2}+\mathrm{M} \\
& \mathrm{HCN}+\mathrm{H} \rightarrow \mathrm{HCN}+\mathrm{NH} \\
& \mathrm{NH}+\mathrm{H} \rightarrow \mathrm{N}+\mathrm{H}_{2} \\
& \text { net } \mathrm{CH}+\mathrm{N}_{2}+2 \mathrm{H} \rightarrow \mathrm{HCN}+\mathrm{N}+\mathrm{H}_{2}
\end{aligned}
$$

which forms $\mathrm{HCN}$, accelerates the association of $\mathrm{H}$ atoms to form $\mathrm{H}_{2}$, and provides a rare case of indirect photolysis of $\mathrm{N}_{2}$ by Lyman-alpha radiation (which produces $\mathrm{CH}$ from $\mathrm{CH}_{4}$ ). These species are among the most abundant photochemical products. To check the effect of this cycle, we will consider a model without this cycle and compare it with a similar basic model.

Transition probabilities of two components of the $\mathrm{N}\left({ }^{2} D\right.$ $\left.\rightarrow{ }^{4} S\right) 5200 \AA$ doublet are

$$
\begin{array}{ll}
\mathrm{N}\left({ }^{2} D_{3 n}\right) \rightarrow \mathrm{N}\left({ }^{4} S\right)+h v & A_{3 / 2}=1.6 \times 10^{-5} \mathrm{~s}^{-1} \\
\mathrm{~N}\left({ }^{2} D_{5 n}\right) \rightarrow \mathrm{N}\left({ }^{4} S\right)+h v & A_{S / 2}=0.7 \times 10^{-5} \mathrm{~s}^{-1}
\end{array}
$$

[e.g., Allen, 1973]. Then a weighted-mean transition probability of $\mathrm{N}\left({ }^{2} D\right)$ is equal to $1.06 \times 10^{-5} \mathrm{~s}^{-1}$ using statistical weights $g=2 J+1$. We discuss this to prevent a further spread of an erroneous value $2.3 \times 10^{-5}=1.6 \times 10^{-5}+0.7 \times 10^{-5}$ in photochemical papers (e.g., Stevens et al. [1992], LYA93, 
Table 2. Reactions in Triton's Ionosphere, Their Rate Coefficients, and Column Rates Normalized to the Surface

\begin{tabular}{|c|c|c|c|}
\hline & Reaction & $\begin{array}{c}\text { ate Coefficient, } \\
\mathrm{cm}^{3} / \mathrm{s}\end{array}$ & $\begin{array}{c}\text { Column Rate, } \\
\mathrm{cm}^{-2} \mathrm{~s}^{-1}\end{array}$ \\
\hline$\overline{72 a}$ & $\mathrm{~N}_{2}+e \rightarrow \mathrm{N}_{2}^{+}+2 e$ & - & $5.64+7^{1}$ \\
\hline $72 b$ & $\rightarrow \mathrm{N}^{+}+\mathrm{N}+2 e$ & - & $1.24+7$ \\
\hline $73 \mathbf{a}$ & $\mathrm{CO}+e \rightarrow \mathrm{CO}^{+}+2 e$ & - & 2295 \\
\hline $73 b$ & $\rightarrow \mathrm{C}^{+}+\mathrm{O}+2 e$ & - & 503 \\
\hline 74 & $\mathrm{~N}+e \rightarrow \mathrm{N}^{+}+2 e$ & - & $6.84+5$ \\
\hline 75 & $\mathrm{C}+e \rightarrow \mathrm{C}^{+}+2 e$ & - & $1.76+4$ \\
\hline 76 & $\mathrm{O}+e \rightarrow \mathrm{O}^{+}+2 e$ & - & $2.35+4$ \\
\hline $77 \mathrm{a}$ & $\mathrm{N}_{2}+h v \rightarrow \mathrm{N}_{2}^{+}+e$ & - & $2.92+7$ \\
\hline $77 \mathrm{~b}$ & $\rightarrow \mathrm{N}^{+}+\mathrm{N}+e$ & - & $4.17+6$ \\
\hline $78 \mathbf{a}$ & $\mathrm{CO}+h v \rightarrow \mathrm{CO}^{+}+e$ & - & 739 \\
\hline $78 b$ & $\rightarrow \mathrm{C}^{+}+\mathrm{O}+e$ & - & 116 \\
\hline 79 & $\mathrm{~N}+h v \rightarrow \mathrm{N}^{+}+e$ & - & $3.88+5$ \\
\hline 80 & $\mathrm{C}+h v \rightarrow \mathrm{C}^{+}+e$ & - & $6.91+4$ \\
\hline 81 & $\mathrm{O}+h v \rightarrow \mathrm{O}^{+}+e$ & - & $1.30+4$ \\
\hline 82 & $\mathrm{~N}_{2}^{+}+\mathrm{H}_{2} \rightarrow \mathrm{N}_{2} \mathrm{H}^{+}+\mathrm{H}$ & $1.3 \times 10^{-9 *}$ & $2.25+7$ \\
\hline 83 & $\mathrm{~N}_{2}^{+}+\mathrm{CO} \rightarrow \mathrm{CO}^{+}+\mathrm{N}_{2}$ & $7.3 \times 10^{-11}$ & $4.78+5$ \\
\hline 84 & $\mathrm{~N}_{2}^{+}+\mathrm{C} \rightarrow \mathrm{C}^{+}+\mathrm{N}_{2}$ & $4 \times 10^{-11} \neq$ & $1.64+6$ \\
\hline 85 & $\mathrm{~N}_{2}^{+}+\mathrm{O} \rightarrow \mathrm{NO}^{+}+\mathrm{N}$ & $1.4 \times 10^{-10}$ & $9.33+6$ \\
\hline 86 & $\mathrm{~N}_{2}^{+}+\mathrm{N} \rightarrow \mathrm{N}^{+}+\mathrm{N}_{2}$ & $10^{-11}$ & $1.75+7$ \\
\hline 87 & $\mathrm{~N}_{2}^{+}+\mathrm{CH}_{4} \rightarrow \mathrm{CH}_{3}^{+}+\mathrm{H}+\mathrm{N}_{2}$ & $1.2 \times 10^{-9} *$ & $1.67+4$ \\
\hline 88 & $\mathrm{~N}_{2}^{+}+\mathrm{HCN} \rightarrow \mathrm{HCN}^{+}+\mathrm{N}_{2}$ & $3.9 \times 10^{-10}$ & 586 \\
\hline 89 & $\mathrm{~N}^{+}+\mathrm{H}_{2} \rightarrow \mathrm{NH}^{+}+\mathrm{H}$ & $3 \times 10^{-10 *}$ & $1.94+7$ \\
\hline 90 & $\mathrm{~N}^{+}+\mathrm{CO} \rightarrow \mathrm{CO}^{+}+\mathrm{N}$ & $9 \times 10^{-10 *}$ & $1.48+7$ \\
\hline 91 & $\mathrm{~N}^{+}+\mathrm{CH}_{4} \rightarrow \mathrm{CH}_{3}^{+}+\mathrm{NH}$ & $10^{-9} *$ & $9.34+3$ \\
\hline 92 & $\mathrm{~N}^{+}+\mathrm{HCN} \rightarrow \mathrm{HCN}^{+}+\mathrm{N}$ & $3.7 \times 10^{-9}$ & $4.45+3$ \\
\hline 93 & $\mathrm{CO}^{+}+\mathrm{H}_{2} \rightarrow \mathrm{HCO}^{+}+\mathrm{H}$ & $1.4 \times 10^{-9}$ & $4.27+6$ \\
\hline 94 & $\mathrm{CO}^{+}+\mathrm{H}^{+} \rightarrow \mathrm{H}^{+}+\mathrm{CO}$ & $7.5 \times 10^{-10}$ & $3.86+5$ \\
\hline 95 & $\mathrm{CO}^{+}+\mathrm{C} \rightarrow \mathrm{C}^{+}+\mathrm{CO}$ & $4 \times 10^{-11 \neq}$ & $1.90+5$ \\
\hline 96 & $\mathrm{CO}^{+}+\mathrm{O} \rightarrow \mathrm{O}^{+}+\mathrm{CO}$ & $1.4 \times 10^{-10}$ & $1.21+6$ \\
\hline 97 & $\mathrm{CO}^{+}+\mathrm{CH}_{4} \rightarrow \mathrm{CH}_{4}^{+}+\mathrm{CO}$ & $1.34 \times 10^{-9}$ & $4.91+3$ \\
\hline 98 & $\mathrm{CO}^{+}+\mathrm{HCN} \rightarrow \mathrm{HCN}^{+}+\mathrm{CO}$ & $3.4 \times 10^{-9}$ & $1.36+3$ \\
\hline 99 & $\mathrm{H}^{+}+\mathrm{O} \rightarrow \mathrm{O}^{+}+\mathrm{H}$ & $8.5 \times 10^{-11 *}$ & $3.92+5$ \\
\hline 100 & $\mathrm{H}^{+}+\mathrm{CH}_{4} \rightarrow \mathrm{CH}_{3}^{+}+\mathrm{H}_{2}$ & $4.15 \times 10^{-9}$ & $8.01+3$ \\
\hline 101 & $\mathrm{H}^{+}+\mathrm{HCN} \rightarrow \mathrm{HCN}^{+}+\mathrm{H}$ & $1.1 \times 10^{-8}$ & $2.47+3$ \\
\hline 102 & $\mathrm{O}^{+}+\mathrm{N}_{2} \rightarrow \mathrm{NO}^{+}+\mathrm{N}$ & $2.8 \times 10^{-12} *$ & $1.53+6$ \\
\hline 103 & $\mathrm{O}^{+}+\mathrm{H}_{2} \rightarrow \mathrm{OH}^{+}+\mathrm{H}$ & $1.6 \times 10^{-9}$ & $9.75+4$ \\
\hline 104 & $\mathrm{O}^{+}+\mathrm{H}^{2} \rightarrow \mathrm{H}^{+}+\mathrm{O}$ & $6 \times 10^{-10 *}$ & $7.71+3$ \\
\hline $105 a$ & $\mathrm{C}^{+}+\mathrm{CH}_{4} \rightarrow \mathrm{C}_{2} \mathrm{H}_{3}^{+}+\mathrm{H}$ & $9.4 \times 10^{-10}$ & $2.72+5$ \\
\hline $105 b$ & $\rightarrow \mathrm{C}_{2} \mathrm{H}_{2}^{+}+\mathrm{H}_{2}$ & $3.6 \times 10^{-10}$ & $1.03+5$ \\
\hline 106 & $\mathrm{C}^{+}+\mathrm{HCN} \rightarrow \mathrm{C}_{2} \mathrm{~N}^{+}+\mathrm{H}$ & $3 \times 10^{-9}$ & $1.76+5$ \\
\hline 107 & $\mathrm{NH}^{+}+\mathrm{N}_{2} \rightarrow \mathrm{N}_{2} \mathrm{H}^{+}+\mathrm{N}$ & $6.5 \times 10^{-10}$ & $1.94+7$ \\
\hline 108 & $\mathrm{~N}_{2} \mathrm{H}^{+}+\mathrm{CO} \rightarrow \mathrm{HCO}^{+}+\mathrm{N}_{2}$ & $8.8 \times 10^{-10}$ & $5.61+6$ \\
\hline 109 & $\mathrm{~N}_{2}^{2} \mathrm{H}^{+}+\mathrm{CH}_{4} \rightarrow \mathrm{CH}_{5}^{+}+\mathrm{N}_{2}^{2}$ & $8.9 \times 10^{-10}$ & $2.62+4$ \\
\hline $110 \mathrm{a}$ & $\mathrm{C}_{2} \mathrm{H}_{2}^{+}+\mathrm{N} \rightarrow \mathrm{CHCN}^{+}+\mathrm{H}$ & $1.5 \times 10^{-10}$ & $6.23+4$ \\
\hline $110 \mathrm{~b}$ & $\rightarrow \mathrm{C}_{2} \mathrm{~N}^{+}+\mathrm{H}_{2}$ & $7.5 \times 10^{-11}$ & $3.12+4$ \\
\hline $110 \mathrm{c}$ & $\rightarrow \mathrm{CH}^{+}+\mathrm{HCN}$ & $2.5 \times 10^{-11}$ & $1.04+4$ \\
\hline 111 & $\mathrm{C}_{2} \mathrm{H}_{3}^{+}+\mathrm{N} \rightarrow \mathrm{CHCN}^{+}+\mathrm{H}_{2}$ & $2.2 \times 10^{-10}$ & $2.72+5$ \\
\hline 112 & $\mathrm{OH}^{+}+\mathrm{N}_{2} \rightarrow \mathrm{N}_{2} \mathrm{H}^{+}+\mathrm{O}$ & $2.4 \times 10^{-10}$ & $9.75+4$ \\
\hline 113 & $\mathrm{C}^{+}+e \rightarrow \mathrm{C}+h v$ & $8 \times 10^{-12 *}$ & $2.26+5$ \\
\hline 114 & $\mathrm{~N}^{+}+e \rightarrow \mathrm{N}+h v$ & $7 \times 10^{-12 *}$ & $4.02+4$ \\
\hline 115 & $\mathrm{~N}_{2}^{+}+e \rightarrow \mathrm{N}+\mathrm{N}$ & $5.7 \times 10^{-8 *}$ & $3.41+7$ \\
\hline 116 & $\mathrm{CO}^{+}+e \rightarrow \mathrm{C}+\mathrm{O}$ & $1.7 \times 10^{-7} *$ & $9.19+6$ \\
\hline 117 & $\mathrm{NO}^{+}+e \rightarrow \mathrm{N}+\mathrm{O}$ & $6.5 \times 1$ & $1.09+7$ \\
\hline 118 & $\mathrm{~N}_{2} \mathrm{H}^{*}+e \rightarrow \mathrm{N}_{2}+\mathrm{H}$ & $6.3 \times 10^{-7 *}$ & $3.64+7$ \\
\hline 119 & $\mathrm{HCO}^{+}+e \rightarrow \mathrm{H}^{+}+\mathrm{CO}$ & $5 \times 10^{-7} *$ & $9.89+6$ \\
\hline 120 & $\mathrm{HCN}^{+}+e \rightarrow \mathrm{H}+\mathrm{CN}$ & $3.5 \times 10^{-7} *$ & $8.86+3$ \\
\hline $121 \mathrm{a}$ & $\mathrm{CHCN}^{+}+e \rightarrow \mathrm{CH}+\mathrm{CN}$ & $2.6 \times 10^{-7} *$ & $1.67+5$ \\
\hline $121 b$ & $\rightarrow \mathrm{C}+\mathrm{HCN}$ & $2.6 \times$ & $1.67+5$ \\
\hline 122 & $\mathrm{C}_{2} \mathrm{~N}^{+}+e \rightarrow \mathrm{CN}+\mathrm{C}$ & $5 \times 10^{-7 *}$ & $2.07+5$ \\
\hline 123 & $\mathrm{CH}^{+}+e \rightarrow \mathrm{C}+\mathrm{H}$ & $5 \times 10^{-7 *}$ & $1.04+4$ \\
\hline 124 & $\mathrm{CH}_{3}^{+}+e \rightarrow \mathrm{CH}_{2}+\mathrm{H}$ & $5 \times 10^{-7 *}$ & $3.41+4$ \\
\hline 125 & $\mathrm{CH}_{4}^{+}+e \rightarrow \mathrm{CH}_{3}^{+}+\mathrm{H}$ & $5 \times 10^{-7} *$ & $4.91+3$ \\
\hline 126 & $\mathrm{CH}_{5}^{+}+e \rightarrow \mathrm{CH}_{3}+\mathrm{H}_{2}$ & $5 \times 10^{-7 *}$ & $2.62+4$ \\
\hline
\end{tabular}

Rate coefficients for ion-molecular reactions are taken from Anicich [1993], and their temperature dependences (if measured) from references therein. Radiative recombination coefficients are from Prasad and Huntress [1980], and dissociative recombination coefficients are from Mitchell [1990] with some values assumed.

* For $T=100 \mathrm{~K}$

$+5.64+7=5.64 \times 10^{7}$

t The value assumed for the basic model.
SS95). Because chemical quenching of $\mathrm{N}\left({ }^{2} D\right)$ is small or nonexistent under the conditions on Triton, we ignore chemical effects of $\mathrm{N}\left({ }^{2} D\right)$.

The formation of CNN (R25) and its reaction with $\mathrm{N}$ is the important chemical cycle of atomic nitrogen loss (LYA93, SS95):

(R25) $\mathrm{C}+\mathrm{N}_{2}+\mathrm{M} \rightarrow \mathrm{CNN}+\mathrm{M}$

(R41) $\mathrm{CNN}+\mathrm{N} \rightarrow \mathrm{CN}+\mathrm{N}_{2}$

(R45) $\frac{\mathrm{CN}+\mathrm{N} \rightarrow \mathrm{C}+\mathrm{N}_{2}}{\text { net } \mathrm{N}+\mathrm{N} \rightarrow \mathrm{N}_{2}}$

LYA93 assumed $k_{41}$ and rate coefficients of $\mathrm{CNN}$ with $\mathrm{H}, \mathrm{O}$, and $\mathrm{C}$ as $10^{-10} \mathrm{~cm}^{3} / \mathrm{s}$ based on comparison with (R45), while SS95 adopted $10^{-11} \mathrm{~cm}^{3} / \mathrm{s}$. We consider $\mathrm{CCO}$ as the best analog for $\mathrm{CNN}$ due to the similarity of the $\mathrm{CO}$ and $\mathrm{N}_{2}$ molecules. The C-CO bond energy is $2.2 \mathrm{eV}$ [Okabe, 1978], and reactions of $\mathrm{CCO}$ with $\mathrm{O}$ and $\mathrm{H}$ are really in the range of $10^{-11}-10^{-10} \mathrm{~cm}^{3} / \mathrm{s}$ [Bauer et al., 1985]. We will use $k=$ $2 \times 10^{-11} \mathrm{~cm}^{3} / \mathrm{s}$ for the reactions of $\mathrm{CNN}$ with $\mathrm{N}, \mathrm{H}, \mathrm{C}$, and $\mathrm{O}$ and ignore the possible interactions of $\mathrm{CNN}$ with hydrocarbons adopted in LYA93. Note that if the $\mathrm{C}-\mathrm{N}_{2}$ bond energy exceeds $1.6 \mathrm{eV}$, then the reaction branch

$\mathrm{CNN}+\mathrm{H} \rightarrow \mathrm{CN}+\mathrm{NH}$

is endothermic. Therefore we ignore this branch (suggested by LYA93 and SS95) and assume $\mathrm{CH}+\mathrm{N}_{2}$ as the only products of the $\mathrm{CNN}+\mathrm{H}$ reaction. $\mathrm{N}-\mathrm{N}$ bonds are very strong; therefore, breaking of these bonds may be a minor branch in the $\mathrm{CNN}+\mathrm{C}$ reaction. Therefore we suggest

(R43) $\mathrm{CNN}+\mathrm{C} \rightarrow \mathrm{C}_{2}+\mathrm{N}_{2}$

instead of $\mathrm{CNN}+\mathrm{C} \rightarrow \mathrm{CN}+\mathrm{CN}$ suggested by LYA93.

Reactions (R47-49) of CN with hydrocarbons [Sims et al., 1993] were observed recently at temperatures down to $25 \mathrm{~K}$. The branching ratio of $\mathrm{C}_{2} \mathrm{H}_{3} \mathrm{CN}$ is equal to 0.2 in the reaction $\mathrm{CN}+\mathrm{C}_{2} \mathrm{H}_{4}$ [Monks et al., 1993], while that of $\mathrm{HC}_{3} \mathrm{~N}$ in (R47) $\mathrm{CN}+\mathrm{C}_{2} \mathrm{H}_{2}$ is considered negligible by Sayah et al. [1988]. HCN is the only nitrile considered in all of the experimental studies of $\mathrm{CN}+\mathrm{C}_{2} \mathrm{H}_{6}$ known to us. Therefore we assume $\mathrm{HCN}$ is the only nitrile in these reactions and neglect the possible production of others.

Recent studies of reactions (R51) and (R52) of C with $\mathrm{C}_{2} \mathrm{H}_{2}$ and $\mathrm{C}_{2} \mathrm{H}_{4}$ by Haider and Husain [1993] are important for Triton's chemistry. The rate coefficients were measured at $300 \mathrm{~K}$, and an order-of-magnitude reduction is adopted by us to apply them to Triton's conditions. The products were not identified in these reactions, and we suggest the most exothermic branches.

A rate coefficient of the key reaction in the $\mathrm{C}^{+}$ionosphere (R84) $\mathrm{N}_{2}^{+}+\mathrm{C} \rightarrow \mathrm{C}^{+}+\mathrm{N}_{2}+4.32 \mathrm{eV}$

is unknown. Based on its similarity to

$$
\mathrm{N}_{2}^{+}+\mathrm{H} \rightarrow \mathrm{H}^{+}+\mathrm{N}_{2}+2.0 \mathrm{eV}
$$

SS95 suggested $k_{84} \approx 10^{-11} \mathrm{~cm}^{3} / \mathrm{s}$. We agree that $k_{84}$ may be as low as $10^{-11}$, but do not see good reasons to preclude higher values. Consider, e.g.,

(R96) $\mathrm{CO}^{+}+\mathrm{O} \rightarrow \mathrm{O}^{+}+\mathrm{CO}+0.4 \mathrm{eV} \quad k_{96}=1.4 \times 10^{-10} \mathrm{~cm}^{3} / \mathrm{s}$ [Fehsenfeld and Ferguson, 1972; Anicich, 1993]. The oxygen atom is a much better analog to $C$ in terms of thermal velocity and electron state than the hydrogen atom is, and $\mathrm{CO}^{+}$is a good analog to $\mathrm{N}_{2}^{+}$. The high exothermicity of (R84) does not preclude a high rate coefficient, e.g.,

$$
\mathrm{H}^{+}+\mathrm{NO} \rightarrow \mathrm{NO}^{+}+\mathrm{H}+4.35 \mathrm{eV} \quad k=1.9 \times 10^{-9} \mathrm{~cm}^{3} / \mathrm{s}
$$

[Fehsenfeld and Ferguson, 1972; Anicich, 1993]. We assume $k_{84}=4 \times 10^{-11} \mathrm{~cm}^{3} / \mathrm{s}$ in our basic model. The same value is adopted to a reaction

(R95) $\mathrm{CO}^{+}+\mathrm{C} \rightarrow \mathrm{C}^{+}+\mathrm{CO}$ 
Some models with smaller and larger values of $k_{84}$ and $k_{95}$ will be considered as well.

Prasad and Huntress [1980] recommend values of $4.4 \times 10^{-12}(300 / T)^{0.6}$ and $3.8 \times 10^{-12}(300 / T)^{0.6} \mathrm{~cm}^{3} / \mathrm{s}$ for radiative recombination coefficients of $\mathrm{C}^{+}$and $\mathrm{N}^{+}$, respectively. We adopt these values, which are larger by a factor of 1.5 at $T$ $=100 \mathrm{~K}$ than $5 \times 10^{-12} \mathrm{~cm}^{3} / \mathrm{s}$ adopted by LYA93. The smaller radiative recombination coefficients facilitate a fit to the measured electron densities.

\section{Model}

Background atmosphere and energy sources. We use in our model the profiles of temperature and $\mathrm{N}_{2}$ density from Krasnopolsky et al. [1993]. Our model is steady state and one-dimensional, and reflects global-mean and orbit-averaged conditions at high solar activity typical of the period before the Voyager 2 observations $\left(F_{10.7 \mathrm{~cm}} \approx 200\right)$. Three sources of dissociation and ionization are considered: the solar EUV radiation, the interstellar background Lyman-alpha radiation with a mean intensity of $340 \mathrm{R}$ (SS95), and precipitation of magnetospheric electrons with a total energy input of $10^{8} \mathrm{~W}$. Solar EUV intensities are taken from Torr and Torr [1985] and interpolated to the solar activity index $F_{10.7} \mathrm{~cm}=200$. We scale the $\mathrm{H}$ Lyman $\alpha$ flux $4.1 \times 10^{8}$ photons $\mathrm{cm}^{-2} \mathrm{~s}^{-1}$ from Lean [1991] by a factor of 1.28 to find the flux in the $1000-1400$ $\AA$ interval. The magnetospheric electron ionization profile is taken from Strobel et al. [1990b], is shifted upward by two scale heights according to Summers and Strobel [1991], and is multiplied by a factor of 0.162 , which reflects a ratio of the global-mean and orbit-averaged electron flux to that near Neptune's magnetic equator in the chosen model of Krasnopolsky et al. [1993]. The photolysis rates are halves of those calculated for solar zenith angle of $60^{\circ}$. The $\mathrm{CO}$ mixing ratio is $3 \times 10^{-4}$ in the basic model. This value is just in the middle of the $10^{-4}-10^{-3}$ range, which may be the most plausible. SS95 prefer $2.5 \times 10^{-4}$, which slightly exceeds their previous upper limit $f_{\mathrm{CO}} \leq 2 \times 10^{-4}$ [Stevens et al., 1992] and is very close to their current upper limit $f_{\mathrm{CO}} \leq 3 \times 10^{-4}$. Uncertainties in the magnetospheric electron energy input and heating efficiencies of some processes are rather large, and we do not understand why the difference between the preferred $\mathrm{CO}$ mixing ratio and its upper limit is so small, with both values based on the thermal balance calculations.

Haze model. An important feature of chemical modeling of Triton is the condensation of hydrocarbons (except $\mathrm{CH}_{4}$ ) and nitriles on the haze particles. Saturation densities of these species are extremely low at $T \approx 40 \mathrm{~K}\left(\sim 10 \mathrm{~cm}^{-3}\right.$ for $\mathrm{C}_{2} \mathrm{H}_{4}$ [Brown and Ziegler, 1979]), and each collision with a particle results in condensation. The condensation rate coefficient is therefore

$$
\tau_{\mathrm{c}}^{-1}=v_{\mathrm{p}} S / 4
$$

where $v_{f}$ is thermal velocity of a molecule, $S$ is the haze specific surface, i.e., a sum of surfaces of all particles per cubic centimeter. The properties of the haze as a function of height were determined by Krasnopolsky et al. [1992] and Krasnopolsky [1993b] up to $30 \mathrm{~km}$ based on the Voyager 2 UVS and TV observations [Herbert and Sandel, 1991; Pollack et al., 1990]. From those data, $\tau_{\mathrm{C}}{ }^{-1}=9 \times 10^{-5} \exp (-$ $h / H) \mathrm{s}^{-1}$. Here $H=14 \mathrm{~km}$ is the atmospheric scale height. This formula can be used below $30 \mathrm{~km}$, and two scenarios are possible above this height. In the first, nucleation and spontaneous condensation occur slightly above $30 \mathrm{~km}$, say, at $40 \mathrm{~km}$, and no particles exist above this height. The second case corresponds to condensation of all locally produced material to grow the particles. We consider this case.

There should be a change in the haze profile near $20 \mathrm{~km}$, where the vertical optical depth of methane is equal to 0.5 at $1216 \AA$. At the slant optical depth $\tau_{\mathrm{CH} 4}>1$ below this level, the production of the condensible species becomes low, and the haze and its specific surface are distributed with the atmospheric scale height $H$ due to variation of the particle sedimentation velocity. Methane becomes optically thin above $20 \mathrm{~km}$, and the haze specific surface is distributed with a scale height

$$
\frac{1}{H_{S}}=\frac{2}{3}\left(\frac{1}{H_{\mathrm{CH} 4}}+\frac{1}{H}\right)
$$

The mean methane scale height at the two observed occultation points is $7 \mathrm{~km}$, and $H_{S}=7 \mathrm{~km}$ as well. We have found a function which approximates rather well the condensation rate coefficient above and below $20 \mathrm{~km}$.

The condensation rate coefficient adopted by LYA93 at 9 $\mathrm{km}$ is equal to $10^{-5} \mathrm{~s}^{-1}$ and is smaller by a factor of 4.7 than our value, which is based on the measurements. Fortunately, they assumed a haze scale height of $10 \mathrm{~km}$, which is just the mean of our values below and above $20 \mathrm{~km}$.

Boundary conditions. Photochemical processes are strongly depleted in the troposphere (below $8 \mathrm{~km}$ ) due to high opacity of the overlying atmosphere to the solar radiation at $\lambda<1400 \AA$, and due to condensation with a time constant which is much smaller than the mixing time. Therefore condensation of photochemical species on the cloud particles (which exist mostly below $8 \mathrm{~km}$ [Rages and Pollack, 1992]) and on Triton's surface is of minor importance and is neglected in our model.

We assume in our basic model that the haze particles are chemically passive. An extreme alternative case, when scavenging of all species except $\mathrm{N}_{2}, \mathrm{CH}_{4}, \mathrm{CO}$, and $\mathrm{H}_{2}$ occurs with efficiency of $100 \%$, will be also considered.

$\mathrm{H}, \mathrm{H}_{2}, \mathrm{C}, \mathrm{N}$, and $\mathrm{O}$ are subject to thermal escape at the upper boundary at $800 \mathrm{~km}$. This boundary is slightly lower than the exobase height of $870 \mathrm{~km}$ [Krasnopolsky et al., 1993]; however, this fact is of minor importance to the results of modeling. All other neutral compounds are assumed to have zero fluxes at the upper boundary.

SS95 argue that Triton's ionopause is rather close to its exobase. Ions reaching the ionopause are swept out by the corotating magnetosphere of Neptune. This process is responsible for the observed decrease of the plasma scale height above $600 \mathrm{~km}$. To account for this process, Yung and Lyons [1990] and Summers and Strobel [1991] assumed an ion escape velocity $v_{i} \approx 5 \times 10^{4} \mathrm{~cm} / \mathrm{s}$, i.e., "at the maximum ambipolar diffusion rate." This velocity is ton high and would severely deplete the $\mathrm{C}^{+}$ionosphere. Therefore LYA93 adopted a minimum ion escape velocity, which is the thermal escape velocity of $10 \mathrm{~cm} / \mathrm{s}$ for $\mathrm{C}^{+}$. Though small $v_{i}$ facilitates modeling of the electron peak density, we assume $v_{i}=150$ $\mathrm{cm} / \mathrm{s}$ in our basic model. This velocity reflects the possible ion escape above the ionopause and helps to reproduce the electron density profile above $600 \mathrm{~km}$.

The diffusion coefficients of neutral species in our models are based on the data taken from Chamberlain and Hunten [1987] and Banks and Kockarts [1973]: $D_{4}=4.87 \times 10^{17}$ $T^{0.698} / n, D_{\mathrm{H} 2}=1.88 \times 10^{17} T^{0.82} / n, D_{\mathrm{N}, \text {, O O }}=10^{17} T^{0.75} / n$, and $D=$ $0.7 \times 10^{17} T^{0.75} / n$ for other neutral molecules. Ambipolar 
diffusion coefficients of ions are calculated using a method described by Atreya [1986]: $D_{\mathrm{H}^{+}}=5 \times 10^{18} / \mathrm{n}, D_{\mathrm{C}+, \mathrm{N}^{+} \mathrm{O}_{+}}=$ $10^{18} / n$. All these values are in $\mathrm{cm}^{2} / \mathrm{s}$, and $n$ is the total number density.

Continuity equations in a spherical atmosphere are solved in our model by a method described by Krasnopolsky [1993a] and Krasnopolsky et al. [1993]. The accuracy of the finite difference method we use depends strongly on the number of steps. The simplest check is the application of this method to species which do not participate in chemical processes. In this case, a decrease in the number density up to height $h$ is given as $(1-\delta / H)^{h / 0}$ instead of $\mathrm{e}^{-h / H}$. Here $H$ is the scale height, assumed constant for the sake of simplicity, and $\delta$ is the altitude step. Then a ratio of the calculated density at the upper boundary to the real one is equal to 0.011 for 50 total steps, 0.145 for 100 steps, 0.29 for 200 steps, and 0.58 for 320 steps. We feel that 58 steps used by LYA93 do not provide sufficient accuracy with our method, and 320 steps will be used.

\section{Eddy Diffusion}

Methane profiles from the UVS solar occultation measurements [Herbert and Sandel, 1991] are used to obtain the eddy diffusion coefficient $K$. There are two competing processes which determine the $\mathrm{CH}_{4}$ profile below $100 \mathrm{~km}$ on Triton: upward transport by eddy and molecular diffusion and photolysis by solar 1000-1400 $\AA$ and Lyman-alpha background radiation. The idea of explaining the measured $\mathrm{CH}_{4}$ profiles by these processes was suggested by Strobel et al. [1990a], who applied it to preliminary data for $\mathrm{CH}_{4}$ and obtained $K=6000 \pm 2000 \mathrm{~cm}^{2} / \mathrm{s}$ for a quantum yield of $\mathrm{CH}_{4}$ photolysis $\gamma=0.6$. SS95 repeated this procedure with the improved methane profiles from Herbert and Sandel [1991] and gave $K=K_{0}\left(n_{0} / n\right)^{1 / 2} \mathrm{~cm}^{2} / \mathrm{s}$, where $K_{0}=1600$ and 1200 $\mathrm{cm}^{2} / \mathrm{s}$ at the egress and ingress occultation points, respectively, and $n$ is the atmospheric gas number density. We modified their method to our model with $\gamma=1.1$. The balance of the methane is determined by its photolysis with column rate (CR) $2.25 \times 10^{8} \mathrm{~cm}^{-2} \mathrm{~s}^{-1}$ (Table 1), its reaction with $\mathrm{CH}((\mathrm{R} 26)$ $\left.\mathrm{CR}=9.5 \times 10^{7} \mathrm{~cm}^{-2} \mathrm{~s}^{-1}\right)$, and by formation of $\mathrm{CH}_{4}$ in ((R20) $\left.\mathrm{CR}=7.2 \times 10^{7} \mathrm{~cm}^{-2} \mathrm{~s}^{-1}\right)$. To account for these processes, an effective yield of methane photolysis is equal to 1.1 . We assume $K=10^{5} \mathrm{~cm}^{2} / \mathrm{s}$ in the troposphere from Yelle et al. [1991], though this does not improve agreement between the calculated and the measured methane profiles. The measured methane densities near the surface are uncertain within a factor of 4, and we will therefore use them as the second fitting parameter (the first one is $K$ ). Local values of the orbit-mean solar flux are used for these calculations. The values of $K$ obtained are rather close for both occultation sites, and we therefore assume them to be equal. The best fit to the measurements is for either $K=2000\left(\mathrm{n} / \mathrm{n}_{0}\right)^{1 / 2} \mathrm{~cm}^{2} / \mathrm{s}$ or $K=4000 \mathrm{~cm}^{2} / \mathrm{s}$. The latter fits slightly better and will be used in our models (Figure 1). Then the homopause is at 32 $\mathrm{km}$, and methane profiles calculated for different $K$ become parallel above the homopause (Figure 1). Our $K$ are rather close to those of SS95, which located the homopause at 35 $\mathrm{km}$ (40-50 $\mathrm{km}$ given in SS95 is not correct). The divergence of the $\mathrm{CH}_{4}$ profiles calculated for different $K$ is much smaller in Figure 1 than in SS95. Our calculations favor a $\mathrm{CH}_{4}$ density of $3.1 \times 10^{11} \mathrm{~cm}^{-3}$ near the surface.

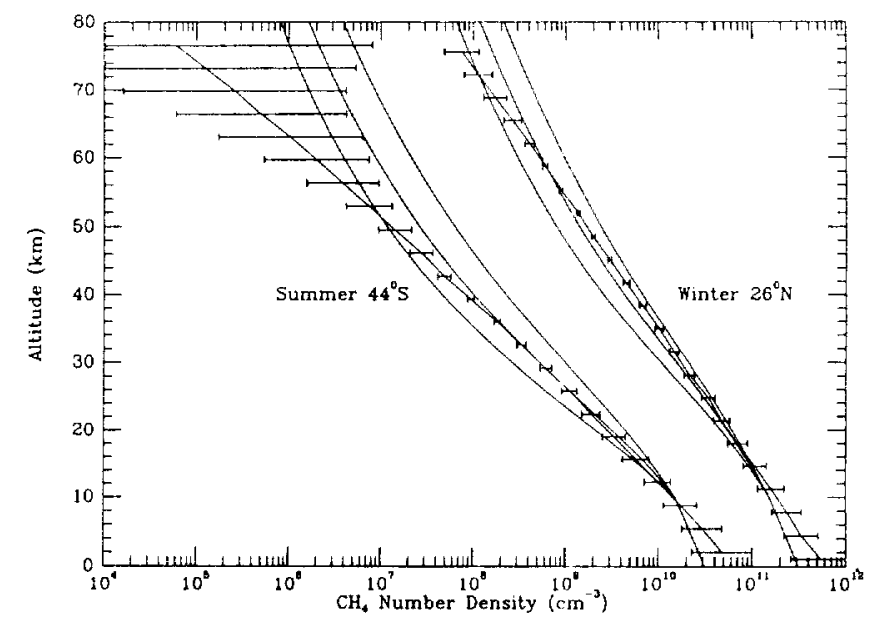

Figure 1. Comparison of the measured profiles of methane [Herbert and Sandel, 1991] with the calculated profiles for $\left[\mathrm{CH}_{4}\right]=3.1 \times 10^{11} \mathrm{~cm}^{-3}$ near the surface and eddy diffusion coefficient $K=2000,4000$, and $8000 \mathrm{~cm}^{2} / \mathrm{s} . K=10^{5} \mathrm{~cm}^{2} / \mathrm{s}$ is assumed below $10 \mathrm{~km}$ [Yelle et al., 1991]. The summer profiles are displaced to the left by a factor of 10 .

\section{Basic Model: Neutral Atmosphere}

Photon and electron dissociation and ionization. Among the reactions in Tables 1 and 2 are 13 dissociation, 10 ionization, and four dissociative ionization processes. To calculate these processes we use absorption and ionization cross sections of $\mathrm{N}_{2}$ and $\mathrm{O}$ from Kirby et al. [1979], of $\mathrm{CO}$ (for $\lambda<800 \AA$ ) from Torr et al. [1979], of $\mathrm{N}$ from Comes and Elzer [1968], and of C from Cantu et al. [1981]. Photolysis rates of $\mathrm{CH}_{4}$ and other hydrocarbons and $\mathrm{HCN}$ may be calculated using their known cross sections and quantum yields (see Table 1). The most difficult ranges are 800-1000 $\AA$, where absorption by $\mathrm{N}_{2}$ bands dominates, and $1000-1100$ $\AA$, where $\mathrm{CO}$ and $\mathrm{C}$ absorb.

Compilations of the $\mathrm{N}_{2}$ cross sections in the $1 \AA$ interval by Kirby et al. [1979] cannot help much at $800-1000 \AA$ because the line widths are smaller by 3 orders of magnitude than $1 \AA$. Detailed modeling of the $\mathrm{N}_{2}$ bands based on the best recent measurements with spectral resolution of $5 \mathrm{~m} \AA$ [Stark et al., 1992] should be done with special care to solve the problem of absorption at 800-1000 $\AA$. An approximation which may be rather good for our purpose is based on the Voyager UVS occultations of Triton which gave the mean optical thickness of $\mathrm{N}_{2}$ in this range as

$$
\tau=1.1 \times 10^{-8} \mathrm{iN}_{2}{ }^{0.434}
$$

where $\left\{\mathrm{N}_{2}\right\}$ is the $\mathrm{N}_{2}$ column density in $\mathrm{cm}^{-2}$ [Krasnopolsky et al., 1993]. The $\mathrm{N}_{2}$ dissociation rate is equal to

$$
p(z)=-\frac{I}{2} e^{-2 \tau} \frac{d \tau}{d z}
$$

where $I$ is the total solar intensity in $800-1000 \AA$ at the orbit of Triton. The rate is maximum at $210 \mathrm{~km}$, and the calculated atmospheric transmission at $800-1000 \AA$ is equal to 0.1 at $200 \mathrm{~km}$ for the geometry of the solar occultation. This transmission agrees with the measured transmission [Krasnopolsky et al., 1993, Figure 1]. LYA93 applied the data from Kirby et al. [1979], finding that the calculated $\mathrm{N}_{2}$ dissocia- 
tion rate is maximum at $470 \mathrm{~km}$. This corresponds to a completely opaque atmosphere for solar occultation at $\mathbf{3 5 0}$ $\mathrm{km}$ and disagrees with the measured transmission of 0.5 at this height (see the same figure).

Even more difficult is the calculation of the dissociation of $\mathrm{CO}$ at 885-1118 $\AA$. The bulk of the dissociation is in the region $1000-1118 \AA$, which is not contaminated by $\mathrm{N}_{2}$ absorption. Four $\mathrm{CO}$ bands centered at 1003, 1052, 1062, and $1076 \AA$ absorb in this range [Fox and Black, 1989]. We calculated a position of the maximum photolysis near $20 \mathrm{~km}$. A strong methane absorption sharply reduces the $\mathrm{CO}$ dissociation below $20 \mathrm{~km}$. The column dissociation rate is equal to $3.8 \times 10^{5} \mathrm{~cm}^{-2} \mathrm{~s}^{-1}$, which is smaller by a factor of 3 than that of LYA93. The CO photodissociation is a minor process in the $\mathrm{CO}$ destruction, and uncertainty of the photodissociation rate is not very important.

Electron energy deposition in $\mathrm{N}_{2}$ was considered by Fox and Victor [1988], and we use their data. For the sake of simplicity, we assume that the $\mathrm{CO}$ electron dissociation, ionization, and dissociative ionization cross sections are equal to those of $\mathrm{N}_{2}$, and $\mathrm{N}, \mathrm{O}$, and $\mathrm{C}$ electron ionization cross sections are equal to half those of $\mathrm{N}_{2}$. These processes are of little importance, and these approximations do not affect the results of modeling. All of the primary processes in the $\mathrm{N}_{2}$ atmosphere are summarized in Table 3. Their vertical profiles are very similar to those calculated by SS95 and are not given here.

Hydrocarbons and HCN. The calculated profiles of the seven most abundant species are shown in Figure 2, the profiles of hydrocarbons and HCN are given in Figure 3, and some active radicals are shown in Figure 4.

One half of the $\mathrm{CH}_{4}$ photolysis events produces methyl $\mathrm{CH}_{3}$. Two thirds of these radicals recombine to $\mathrm{CH}_{4}$ and the rest to ethane $\mathrm{C}_{2} \mathrm{H}_{6}$. These three-body reactions occur mostly below $50 \mathrm{~km}$, and almost all ethane condenses on the haze particles with a precipitation rate of $28 \mathrm{~g} / \mathrm{cm}^{2} / \mathrm{b} . \mathrm{y}$. The other half of the $\mathrm{CH}_{4}$ photolysis events forms $\mathrm{CH}$, which reacts with $\mathrm{CH}_{4}$ (R26). The reaction product, ethylene $\mathrm{C}_{2} \mathrm{H}_{4}$, condenses with a rate of $135 \mathrm{~g} / \mathrm{cm}^{2} / \mathrm{b}$.y. Two percent of the $\mathrm{C}_{2} \mathrm{H}_{4}$ photodissociates and reacts with $\mathrm{C}$ (R52) to form acetylene $\mathrm{C}_{2} \mathrm{H}_{2}$. Acetylene condenses mostly below $50 \mathrm{~km}$ with a rate of $1.3 \mathrm{~g} / \mathrm{cm}^{2} / \mathrm{b} . y$. and reacts with $\mathrm{C}$ (R51) above $50 \mathrm{~km}$. Both $\mathrm{C}_{2} \mathrm{H}_{4}$ and $\mathrm{C}_{2} \mathrm{H}_{2}$ have similar production and loss rates above $50 \mathrm{~km}((\mathrm{R} 52)$ and $\mathrm{R}(51))$; therefore their profiles coincide in this region. A sixth of the $\mathrm{CH}$ radicals forms HCN via the (R24), (R60) cycle (see section 3), which starts from the reaction of $\mathrm{CH}$ with $\mathrm{N}_{2}$. Obviously this source of $\mathrm{HCN}$ is stronger (by a factor of 50 in this model) than the

Table 3. Column Production Rates of $\mathrm{N}_{2}^{+}, \mathrm{N}^{+}$, and $\mathrm{N}$

\begin{tabular}{lcc}
\hline Process & Column Rate \\
\hline Magnetospheric electron ionization & 6.9 \\
Photo- and photoelectron ionization & 2.9 \\
Photo- and photoelectron dissociative ionization & 0.42 \\
Photodissociation $800-1000 \AA$ & 1.8 \\
Photoelectron dissociation & & 0.91 \\
& & \\
Production of $\mathrm{N}^{+}$ & 15 & $(5.8)$ \\
Production of $\mathrm{N}_{2}^{+}$ & 8.6 & $(2.9)$ \\
Production of $\mathrm{N}^{+}$ & 1.7 & $(0.42)$ \\
\hline
\end{tabular}

Rates are in units of $10^{\prime} \mathrm{cm}^{-2} \mathrm{~s}^{-1}$ normalized to the surface. Numbers in parentheses are for the solar model.

* Production of $\mathrm{N}_{2}{ }^{+} 82 \%$, production of $\mathrm{N}^{+} 18 \%$, electron impact dissociation $60 \%$ of this value.

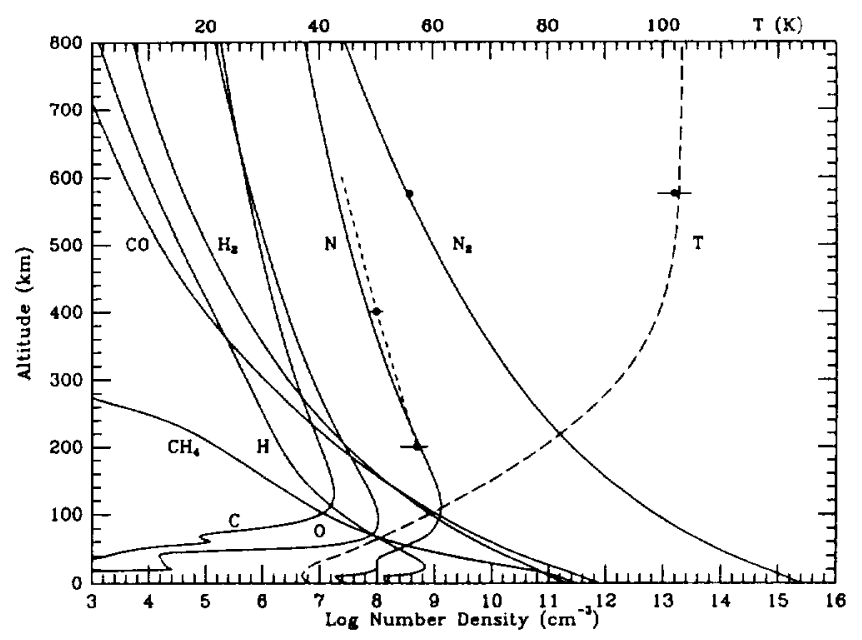

Figure 2. Composition of Triton's atmosphere: the most abundant species. The $\mathrm{N}_{2}$ and $T$ profiles and the measured $\mathrm{N}$ profile (short dashes), $\mathrm{N}_{2}$, and $T$ at $575 \mathrm{~km}$ are from Krasnopolsky et al. [1993].

reactions $\mathrm{N}+\mathrm{CH}_{3}, \mathrm{CH}_{2}((\mathrm{R} 27)$, (R30), and (R59)). HCN is rather inert, and its sinks are condensation below $50 \mathrm{~km}$ with a rate of $29 \mathrm{~g} / \mathrm{cm}^{2} / \mathrm{b}$.y. and reactions with ions above 200 $\mathrm{km}$. Coincidence of the $\mathrm{HCN}$ and $\mathrm{C}_{2} \mathrm{H}_{6}$ profiles below $40 \mathrm{~km}$ (Figure 3 ) is accidental. A photosensitized dissociation of $\mathrm{CH}_{4}$ [Yung et al., 1984] via

(R2) $\mathrm{C}_{2} \mathrm{H}_{2}+h v \rightarrow \mathrm{C}_{2} \mathrm{H}+\mathrm{H}$

(R70) $\mathrm{C}_{2} \mathrm{H}+\mathrm{CH}_{4} \rightarrow \mathrm{C}_{2} \mathrm{H}_{2}+\mathrm{CH}_{3}$ net $\mathrm{CH}_{4}+h v \rightarrow \mathrm{CH}_{3}+\mathrm{H}$

is strongly depleted due to condensation of $\mathrm{C}_{2} \mathrm{H}_{2}$ and loss of $\mathrm{C}_{2} \mathrm{H}$ in the reactions with $\mathrm{N}$ and $\mathrm{O}$.

Atomic and molecular hydrogen. According to section 2 , the production of hydrogen in both forms is equal to $2.25 \times 10^{8} \times 2 \times 1.1=5 \times 10^{8}$ atoms $/\left(\mathrm{cm}^{2} \mathrm{~s}\right)$. Here the first term is the total global-mean $1000-1400 \AA$ photon flux, two hydrogen atoms are released per photon, and 1.1 is the yield of methane photolysis. Hydrogen has no important sinks except thermal escape; therefore we know a priori the total hydrogen escape rate. Atmospheric and ionospheric reactions result in mostly mutual transformations between atomic and

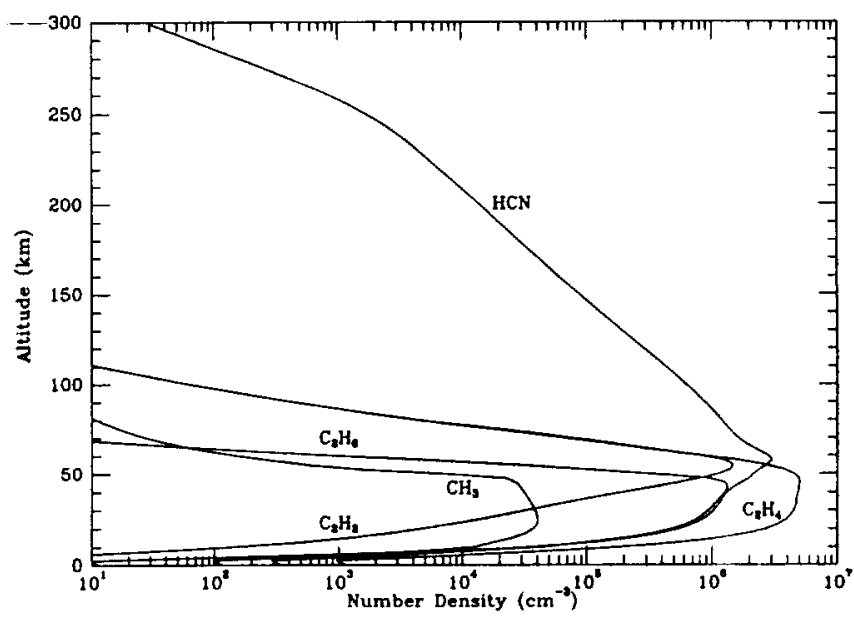

Figure 3. Composition of Triton's atmosphere: photochemically produced hydrocarbons, $\mathrm{HCN}$, and $\mathrm{CH}_{3}$. 


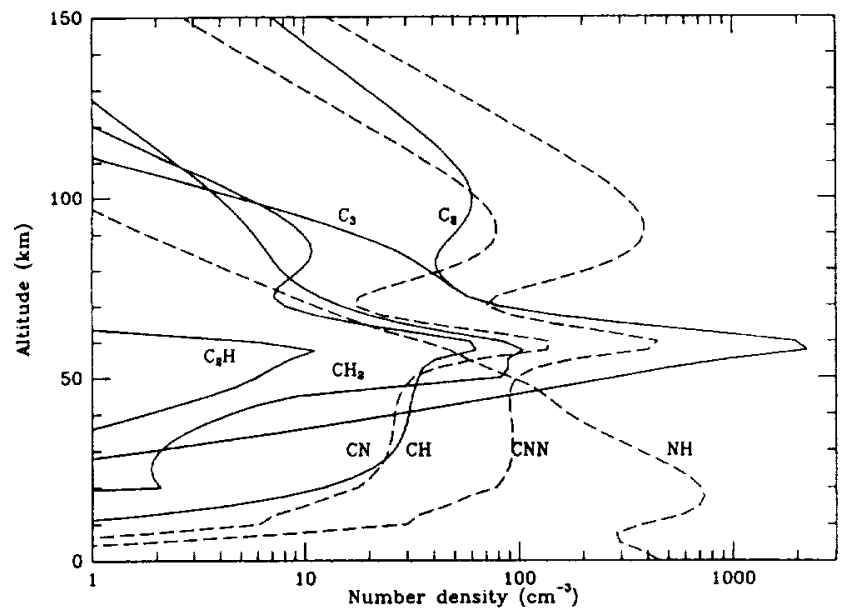

Figure 4. Composition of Triton's atmosphere: diatomic and triatomic radicals.

molecular hydrogen with a small net effect on the sum of these species. Molecular hydrogen is formed from $\mathrm{H}$ atoms below $100 \mathrm{~km}$ by the three-body reaction (R12) and by the reaction (R37) $\mathrm{NH}+\mathrm{H} \rightarrow \mathrm{N}+\mathrm{H}_{2}$. $\mathrm{NH}$ is produced by the $\mathrm{CH}+\mathrm{N}_{2}$ cycle and by the three-body reaction (R16). Reactions of $\mathrm{N}_{2}{ }^{+}, \mathrm{N}^{+}$, and $\mathrm{CO}^{+}$with $\mathrm{H}_{2}$ result in its indirect photolysis. Balances of production and loss of atomic and molecular hydrogen (normalized to the surface) are shown in Tables 4 and 5 . These tables as well as similar tables for other species discussed below include only the main processes, so the balances of production and loss are not exact. Complete data for the column reaction rates from Tables 1 and 2 may be used in more careful calculations if needed. The total hydrogen escape coincides with its production. The $\mathrm{H}_{2}$ mixing ratio is rather constant with height due to the diffusion-limiting flow. The $\mathrm{H}$ profile is maximum at $25 \mathrm{~km}$. A factor of 5 decrease at the surface shows that both downward flux of $\mathrm{H}$ and locally produced $\mathrm{H}$ atoms recombine almost totally below $50 \mathrm{~km}$.

Atomic nitrogen. The calculated profile of $\mathrm{N}$ is compared with the measured profile [Krasnopolsky et al., 1993] in Figure 2. The measured profile has number densities $(1 \pm$ $0.25) \times 10^{8} \mathrm{~cm}^{-3}$ at $400 \mathrm{~km}$ and $(5 \pm 2.5) \times 10^{8} \mathrm{~cm}^{-3}$ at $200 \mathrm{~km}$, which agree with the calculated densities $7.2 \times 10^{7} \mathrm{~cm}^{-3}$ and $5.7 \times 10^{8} \mathrm{~cm}^{-3}$, respectively. Krasnopolsky et al. claimed that the profile should correspond to diffusion equilibrium above $470 \mathrm{~km}$, where the measurements were rather uncertain. SS95 are doubtful of this extrapolation. The calculated profile shows that the extrapolation from $470 \mathrm{~km}$ to the exobase is accurate within $5 \%$.

Table 4. Main Production and Loss of $\mathrm{H}$

\begin{tabular}{lc}
\hline Process & Column Rate \\
\hline $\mathrm{CH}_{4}+h \nu(\gamma=0.996)$ & 2.24 \\
$\mathrm{CH}_{4}+\mathrm{CH} \rightarrow \mathrm{C}_{2} \mathrm{H}_{4}+\mathrm{H}$ & 0.94 \\
lon reactions & 0.93 \\
Total production & 4.11 \\
& \\
$\left(\mathrm{H}+\mathrm{H}+\mathrm{M} \rightarrow \mathrm{H}_{2}+\mathrm{M}\right) \times 2$ & 1.37 \\
$\mathrm{H}+\mathrm{CH}+\mathrm{M} \rightarrow \mathrm{CH}_{4}+\mathrm{M}$ & 0.72 \\
$\left(\mathrm{NH}+\mathrm{H} \rightarrow \mathrm{N}+\mathrm{H}_{2}\right) \times 2$ & 0.92 \\
Escape & 1.04 \\
Total loss & 4.05 \\
\hline
\end{tabular}

Values are in units of $10^{8} \mathrm{~cm}^{-2} \mathrm{~s}^{-1}$.
Table 5. Main Production and Loss of $\mathrm{H}_{2}$

\begin{tabular}{ll}
\hline Process & Column Rate \\
\hline $\mathrm{CH}_{4}+h \nu(\gamma=0.514)$ & 1.32 \\
$\mathrm{H}+\mathrm{H}+\mathrm{M} \rightarrow \mathrm{H}_{2}+\mathrm{M}$ & 0.68 \\
$\mathrm{NH}+\mathrm{H} \rightarrow \mathrm{N}+\mathrm{H}_{2}$ & 0.46 \\
Total production & 2.46 \\
& \\
Ion reactions & 0.46 \\
Escape & 1.96 \\
Total loss & 2.42 \\
\hline \multicolumn{2}{r|}{ Values are in units of in $10^{8} \mathrm{~cm}^{-2} \mathrm{~s}^{-1}}$.
\end{tabular}

Sources and sinks of $\mathrm{N}$ are given in Table 6. The structure of the profile below $50 \mathrm{~km}$ is due to indirect photolysis of $\mathrm{N}_{2}$ via the $\mathrm{CH}+\mathrm{N}_{2}$ cycle discussed in section 2. Atomic nitrogen loss is due to the three-body association reaction (R11) and catalytic cycles with $\mathrm{C}, \mathrm{O}$, and $\mathrm{H}$. The $\mathrm{C}$ cycle, which includes the reactions ( $R 25$ ), (R41), and (R45), was discussed in section 3 . The $O$ cycle is represented by the reactions

(R55)

(R57)

$$
\begin{aligned}
& \mathrm{N}+\mathrm{O} \rightarrow \mathrm{NO}+\mathrm{h} v \\
& \mathrm{~N}+\mathrm{NO} \rightarrow \mathrm{N}_{2}+\mathrm{O} \\
& \text { net } \mathrm{N}+\mathrm{N} \rightarrow \mathrm{N}_{2}
\end{aligned}
$$

The $\mathrm{H}$ cycle is similar, except for the three-body formation of NH. The oxygen and carbon catalytic cycles are of comparable importance, and each provides one third of the atomic nitrogen loss each. The carbon cycle was dominant in LYA93 (96\%) and minor in SS95. The smaller role of the carbon cycle in our model than in LYA93 may be due to a weaker temperature dependence adopted for $k_{25}$ and smaller $k_{41}$ in our model. Another loss mechanism for $\mathrm{N}$ is thermal escape, which is equal to $7.7 \times 10^{24} \mathrm{~s}^{-1}$ and agrees with the measured value of $(1 \pm 0.3) \times 10^{25} \mathrm{~s}^{-1}$.

Carbon monoxide, atomic oxygen and carbon. As discussed above, the carbon monoxide loss rate by direct photodissociation and ionization is $3.8 \times 10^{5} \mathrm{~cm}^{-2} \mathrm{~s}^{-1}$. A chargeexchange reaction of $\mathrm{CO}$ with $\mathrm{N}_{2}^{+}$is of comparable importance $\left(4.8 \times 10^{5} \mathrm{~cm}^{-2} \mathrm{~s}^{-1}\right)$, while that with $\mathrm{N}^{+}$is the dominant loss process with a column loss rate of $1.5 \times 10^{7} \mathrm{~cm}^{-2} \mathrm{~s}^{-1}$. At a rate of $6 \times 10^{6} \mathrm{~cm}^{-2} \mathrm{~s}^{-1}, \mathrm{CO}$ molecules are given back to the atmosphere by charge exchange of $\mathrm{CO}^{+}$with $\mathrm{H}_{2}, \mathrm{C}, \mathrm{O}, \mathrm{H}$, $\mathrm{CH}_{4}$ and by recombination of $\mathrm{HCO}^{+}$. Carbon monoxide is formed by reactions of atomic oxygen with $\mathrm{CNN}$ and $\mathrm{CN}$ $\left(4 \times 10^{6} \mathrm{~cm}^{-2} \mathrm{~s}^{-1}\right)$ and with $\mathrm{CH}_{x}$ radicals $\left(5 \times 10^{6} \mathrm{~cm}^{-2} \mathrm{~s}^{-1}\right)$. The $\mathrm{CO}$ mixing ratio in the upper atmosphere is smaller than near the surface due to large ionospheric losses. The total CO loss

Table 6. Main Production and Loss of N

\begin{tabular}{ll}
\hline Process & Column Rate \\
\hline $\mathrm{N}_{2}+(h v, e) \rightarrow \mathrm{N}, \mathrm{N}^{+}$ & 1.70 \\
The $\mathrm{CH}+\mathrm{N}_{2}$ cycle & 0.20 \\
$\left(\mathrm{~N}_{2}^{+}+(e, \mathrm{O})\right) \times 2$ & 0.87 \\
Total production & 2.77 \\
& \\
$\left(\mathrm{~N}+\mathrm{NO} \rightarrow \mathrm{N}_{2}+\mathrm{O}\right) \times 2$ & 1.00 \\
$\left(\mathrm{~N}+\mathrm{CN} \rightarrow \mathrm{N}_{2}+\mathrm{C}\right) \times 2$ & 0.90 \\
$\left(\mathrm{~N}+\mathrm{N}+\mathrm{M} \rightarrow \mathrm{N}_{2}+\mathrm{M}\right) \times 2$ & 0.33 \\
$\left(\mathrm{~N}+\mathrm{NH} \rightarrow \mathrm{N}_{2}+\mathrm{H}\right) \times 2$ & 0.21 \\
Escape & 0.34 \\
Total loss & 2.77 \\
\hline Values a &
\end{tabular}
Values are in units of $10^{8} \mathrm{~cm}^{-2} \mathrm{~s}^{-1}$. 
is balanced by its production with a small difference due to the oxygen escape at the rate of $1.9 \times 10^{5} \mathrm{~cm}^{-2} \mathrm{~s}^{-1}$, and due to formation and precipitation of $\mathrm{CO}_{2}$ at $5.3 \times 10^{3} \mathrm{~cm}^{-2} \mathrm{~s}^{-1}$. This difference is supplied by evaporation of the surface ice. The net effect of the photochemistry is the loss of $0.3 \mathrm{~g} /\left(\mathrm{cm}^{2}\right.$ b.y.) of carbon monoxide. The production and condensation of $\mathrm{CO}_{2}$ are extremely low and cannot be responsible for the observed $\mathrm{CO}_{2}$ in the ice [Cruikshank et al., 1993].

Atomic oxygen (Table 7) is formed by dissociative recombination of $\mathrm{CO}^{+}$and by photolysis of $\mathrm{CO}$ mostly at $1000-1080 \AA$. The latter has a strong cutoff below $20 \mathrm{~km}$ where methane absorbs. We assumed no $\mathrm{CO}$ photolysis below $20 \mathrm{~km}$, and the profile structure in the lowest $50 \mathrm{~km}$ reflects the effects of the $\mathrm{CO}$ photolysis. Oxygen is removed mostly in the reactions with $\mathrm{CH}_{\mathrm{x}}$ and $\mathrm{CN}_{\mathrm{x}}$ radicals.

The sources of atomic carbon (Table 8) are $\mathrm{CH}_{4}, \mathrm{CO}$, and $\mathrm{HCN}$ photolysis (the latter ends by $(\mathrm{R} 45) \mathrm{CN}+\mathrm{N})$, reactions of $\mathrm{CH}$ with $\mathrm{N}$ and $\mathrm{H}((\mathrm{R} 32)$, (R33)), and recombinations of $\mathrm{CO}^{+}$and some other ions. Another source is the cycle

(R51) $\mathrm{C}_{2} \mathrm{H}_{2}+\mathrm{C} \rightarrow \mathrm{C}_{3}+\mathrm{H}_{2}$

(R65) $\quad \mathrm{C}_{3}+\mathrm{N} \rightarrow \mathrm{CN}+\mathrm{C}_{2}$

(R63) $\mathrm{C}_{2}+\mathrm{N} \rightarrow \mathrm{CN}+\mathrm{C}$

(R45)

$$
\begin{aligned}
& \frac{\left(\mathrm{CN}+\mathrm{N} \rightarrow \mathrm{N}_{2}+\mathrm{C}\right) \times 2}{\text { net } \mathrm{C}_{2}+4 \mathrm{~N} \rightarrow 2 \mathrm{H}_{2}+2(} \\
& \text { net } \mathrm{C}_{2} \mathrm{H}_{2}+4 \mathrm{~N} \rightarrow 2 \mathrm{~N}_{2}+2 \mathrm{C}+\mathrm{H}_{2}
\end{aligned}
$$

This cycle is questionable because products of (R51) are not known, and those suggested produce the highest exothermicity. This cycle provides $10 \%$ total production of carbon atoms and is not of crucial importance for the model. Carbon is lost in reactions of CNN with $\mathrm{O}$ and $\mathrm{H}$ (because CNN is formed by $\mathrm{C}+\mathrm{N}_{2}+\mathrm{M}$ and mostly gives carbon back in $\mathrm{CNN}+\mathrm{N}$ and $\mathrm{CN}+\mathrm{N}$ ), in (R53) $\mathrm{C}_{2} \mathrm{H}_{4}+\mathrm{C}$, and in charge exchange with $\mathrm{N}_{2}{ }^{+}$and $\mathrm{CO}^{+}$, with minor contributions from some other processes. A quarter of the $\mathrm{C}$ production escapes. Escape of carbon is greater by a factor of 25 than that of oxygen (due to the difference in their masses) and is supplied by methane.

Diatomic and triatomic radicals. The most important of these radicals are shown in Figure 4. Many of these species have maxima at $60 \mathrm{~km}$ caused by the reactions (R51), (R52) $\mathrm{C}_{2} \mathrm{H}_{2}, \mathrm{C}_{2} \mathrm{H}_{4}+\mathrm{C}$. Carbon atoms (and $\mathrm{CH}_{2}$ ) are released rather than lost in these reactions; this fact impacts the densities of all carbon-bearing radicals and is seen even in the $C$ profile (Figure 2).

\section{Ionosphere}

The column ionization rate normalized to the surface is equal to $10^{8} \mathrm{~cm}^{-2} \mathrm{~s}^{-1}$ (Table 3), with a ratio of solar to

Table 7. Main Production and Loss of $\mathrm{O}$

\begin{tabular}{ll}
\hline Process & Column Rate \\
\hline $\mathrm{CO}^{+}+e \rightarrow \mathrm{C}+\mathrm{O}$ & 9.19 \\
$\mathrm{CO}+h v \rightarrow \mathrm{C}+\mathrm{O}$ & 0.38 \\
Total production & 9.57 \\
& \\
$\mathrm{O}+\left(\mathrm{CH}, \mathrm{CH}_{2}, \mathrm{CH}_{3}, \mathrm{C}_{2} \mathrm{H}_{4}\right)$ & 5.12 \\
$\mathrm{O}+\left(\mathrm{CN}, \mathrm{CNN}^{2}\right.$ & 3.98 \\
$\mathrm{O}+\left(\mathrm{C}_{2}, \mathrm{C}_{3}\right)$ & 0.16 \\
$\mathrm{O}+\mathrm{O}+\mathrm{M} \rightarrow \mathrm{O}_{2}+\mathrm{M}$ & 0.15 \\
Escape & 0.19 \\
Total loss & 9.60 \\
\hline \multicolumn{2}{c}{ Values are in units of $10^{6} \mathrm{~cm}^{-2} \mathrm{~s}^{-1}}$.
\end{tabular}

Table 8. Main Production and Loss of $\mathrm{C}$

\begin{tabular}{ll}
\hline Process & Column Rate \\
\hline $\mathrm{CO}+h v \rightarrow \mathrm{C}+\mathrm{O}$ & 0.38 \\
$\mathrm{CH}_{4}+h v \rightarrow \mathrm{C}+\mathrm{H}_{2}+\mathrm{H}_{2}$ & 0.90 \\
$\mathrm{CH}+\mathrm{H} \rightarrow \mathrm{H}_{2}+\mathrm{C}$ & 2.82 \\
$\mathrm{CH}+\mathrm{N} \rightarrow \mathrm{H}+\mathrm{CN}$ & 1.91 \\
$\left(\mathrm{C}_{2} \mathrm{H}_{2}+\mathrm{C}\right) \times 2$ & 2.04 \\
$\mathrm{CO}^{+}+e \rightarrow \mathrm{C}+\mathrm{O}$ & 9.19 \\
Other ion recombinations & 0.61 \\
Total production & 17.8 \\
& \\
$\mathrm{C}+\mathrm{C}_{2} \mathrm{H}_{4} \rightarrow \mathrm{C}_{2} \mathrm{H}_{2}+\mathrm{CH}_{2}$ & 1.47 \\
$\mathrm{CNN}{ }^{+}+(\mathrm{H}, \mathrm{O}) \rightarrow \mathrm{N}_{2}+(\mathrm{CH}, \mathrm{CO})$ & 9.00 \\
$\mathrm{C}+\left(\mathrm{N}_{2}^{+}, \mathrm{CO}^{+}\right) \rightarrow \mathrm{C}^{+}+\left(\mathrm{N}_{2}, \mathrm{CO}\right)$ & 1.42 \\
Escape & 4.68 \\
Total loss & 16.6 \\
\hline \multicolumn{2}{l}{ Values are in units of $10^{6} \mathrm{~cm}^{-2} \mathrm{~s}^{-1}$} \\
$\quad$ The reaction $\mathrm{CN}+\mathrm{N} \rightarrow \mathrm{N}_{2}+\mathrm{C}$ ends this cycle. \\
$\quad+$ These cycles begin from $\mathrm{C}^{+} \mathrm{N}_{2}+\mathrm{M} \rightarrow \mathrm{CNN}+\mathrm{M}$.
\end{tabular}

magnetospheric electron rates of 1:2. If the observed ionosphere, with a peak electron density of $(3.5 \pm 1) \times 10^{4} \mathrm{~cm}^{-3}$ at $340 \mathrm{~km}$, consisted of molecular ions, it would require an ionization rate larger by 2 orders of magnitude than the above value due to rapid dissociative recombination of molecular ions. Therefore atomic ions having very slow radiative recombination rates dominate the ionosphere.

Lyons et al. [1992] established the importance of atomic carbon in the formation of the ionosphere. $\mathrm{C}^{+}$is formed by charge exchange between $\mathrm{N}_{2}{ }^{+}$and $\mathrm{C}(\mathrm{R} 84)$ and is removed by reactions with $\mathrm{CH}_{4}$ and $\mathrm{HCN}((\mathrm{R} 105),(\mathrm{R} 106))$. $\mathrm{C}^{+}$ions dominate in their model of the ionosphere, their lifetime is rather long, and the calculated electron densities fit the measured values even without ionization by magnetospheric electrons. However, the reaction (R84) rate coefficient must be very large $\left(k_{84}=10^{-9} \mathrm{~cm}^{3} / \mathrm{s}\right)$ to facilitate production of $\mathrm{C}^{+}$ ions.

The introduction of CO has many important aspects to the ionosphere. The reaction with $\mathrm{CO}$ (R90) becomes a principal sink of $\mathrm{N}^{+}$, substantially lowering its densities. Recombination of $\mathrm{CO}^{+}$increases the atomic carbon densities at 200-400 $\mathrm{km}$, and it becomes possible to fit the measured electron densities with reasonable values of $\mathrm{k}_{84,95} . \mathrm{CO}^{+}, \mathrm{HCO}^{+}$, and $\mathrm{NO}^{+}$become important molecular ions. $\mathrm{H}^{+}$ions are supressed by rapid charge exchange with atomic oxygen (R99), with subsequent reaction between $\mathrm{O}^{+}$and $\mathrm{N}_{2}$. Reaction (R99) is slightly endothermic, and we therefore reduce its rate coefficient to a value appropriate at $100 \mathrm{~K}$. The time constant for $\mathrm{C}^{+}$ions above $250 \mathrm{~km}$ is much longer than a period between passes of the magnetic equator ( 7 hours), and temporal variations of electron density become small. This corresponds to the global mean and orbit-averaged conditions typical of our model.

In our model, $\mathrm{C}^{+}$is a dominant ion (Figure 5), and its balance is considered in Table 9. As in Lyons et al. [1992], the main source of $\mathrm{C}^{+}$is charge exchange between $\mathrm{N}_{2}^{+}$and $C$. The rate coefficient of this reaction is a free parameter to fit the measured electron density profiles. The contribution of the similar reaction with $\mathrm{CO}^{+}$instead of $\mathrm{N}_{2}^{+}$with the same rate coefficient is smaller by an order of magnitude. The total production of $\mathrm{C}^{+}$is only about $2 \%$ of the total ionization rate. The chemical loss is by reactions ( $\mathrm{R} 105)$, ( $\mathrm{R} 106)$ with $\mathrm{CH}_{4}$ and $\mathrm{HCN}$, and radiative recombination. The 


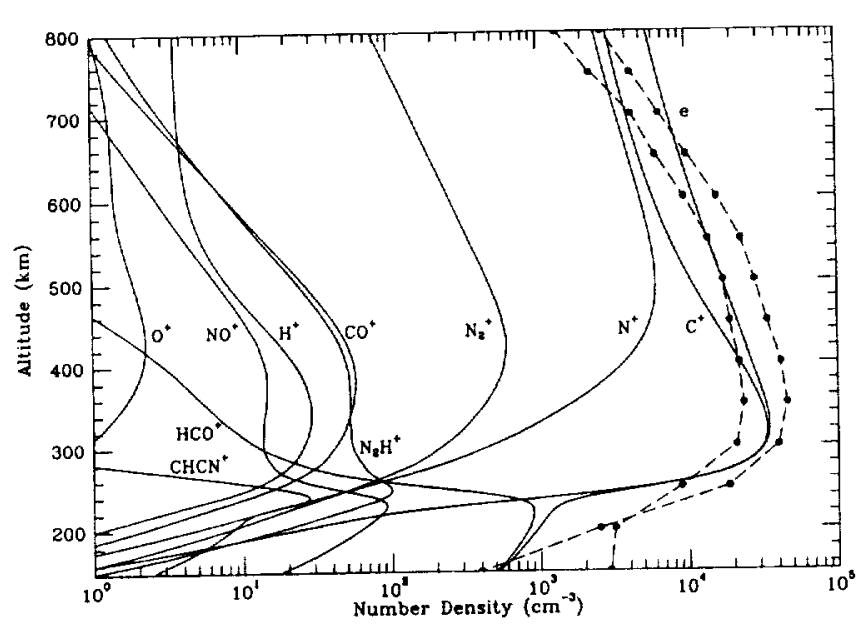

Figure 5. Composition of Triton's ionosphere. The measured electron density profiles [Tyler et al., 1989] are also shown.

strongest sink in our model is the ion escape. As discussed in section 4, the escape velocity is unknown and is chosen as $150 \mathrm{~cm} / \mathrm{s}$ to better fit the shape of the electron density profile between 400 and $700 \mathrm{~km}$. Besides, if the ionopause is really close to the exobase (SS95), then the ion escape velocity should substantially exceed the thermal escape velocity. If the assumed escape velocity is much smaller than $150 \mathrm{~cm} / \mathrm{s}$, then the calculated electron density at $700 \mathrm{~km}$ becomes larger by a factor of 2 . A significant reduction of the ion escape velocity makes it possible to reduce $k_{84,95}$ by a factor of 3 with the same electron densities below $400 \mathrm{~km}$, while the densities near $700 \mathrm{~km}$ become larger by a factor of 2 .

In our model, $\mathrm{N}^{+}$and $\mathrm{C}^{+}$densities are comparable above $500 \mathrm{~km}$, where loss of $\mathrm{N}^{+}$is small due to low densities of $\mathrm{CO}$ and $\mathrm{H}_{2}$, and are similar to SS95 in this respect. While the bulk ionosphere is of an $F$ type, the region below 240 $\mathrm{km}$ consists of molecular ions and is thus of $E$ type. As discussed above, the primary ions $\mathrm{N}_{2}^{+}$and $\mathrm{N}^{+}$react mostly with either $\mathrm{H}_{2}$ forming $\mathrm{N}_{2} \mathrm{H}^{+}$(in the case of $\mathrm{N}^{+}$, $\mathrm{NH}^{+}$ions formed react with $\mathrm{N}_{2}$ to produce $\mathrm{N}_{2} \mathrm{H}^{+}$) or $\mathrm{CO}$ to yield $\mathrm{CO}^{+}$. The main sinks of $\mathrm{N}_{2} \mathrm{H}^{+}$and $\mathrm{CO}^{+}$in the lower ionosphere are reactions with $\mathrm{CO}$ and $\mathrm{H}_{2}$, respectively. A product of these reactions, $\mathrm{HCO}^{+}$, becomes the major ion in the $E$ region.

\section{Other Models}

Some parameters of our model are rather uncertain, and we have therefore calculated models with different values of the parameters. The main properties of these models are shown in Table 10. Model 1 is the basic model without the $\mathrm{CH}+\mathrm{N}_{2}$ cycle $\left(k_{60}=0\right.$ for this model $)$. Evidently, formation and sedimentation of HCN becomes smaller by a factor of 50 than that in the basic model. More $\mathrm{CH}$ radicals react with $\mathrm{CH}_{4}$ to form $\mathrm{C}_{2} \mathrm{H}_{4}$, and $\mathrm{H}$ atoms released in this reaction react with $\mathrm{CH}_{3}$, reducing the production of ethane. The other principal properties of the model remain unchanged.

Model 2 is our basic model without the reaction (R25) C $+\mathrm{N}_{2}+\mathrm{M}$. The formation of CNN affects loss of $\mathrm{C}$ and $\mathrm{O}$ via reactions (R42), (R44) with $\mathrm{H}$ and $\mathrm{O}$. Carbon and oxygen densities are larger in model 2 than in the basic model. This results in a small increase in the $C^{\prime}$ and electron densities. The loss of nitrogen becomes smaller (due to the absence of the CNN cycle) and larger (due to increase of the oxygen cycle; see Table 6) with a net increase by only $4 \%$.

Chemically passive haze particles were assumed in the basic model, and condensation of only $\mathrm{C}_{2} \mathrm{H}_{\mathrm{x}}$ and $\mathrm{HCN}$ was allowed to occur on these particles. Model 3 assumes that all species except $\mathrm{N}_{2}, \mathrm{CH}_{4}, \mathrm{CO}$, and $\mathrm{H}_{2}$ are scavenged by the haze at the maximum possible rate. The strongest effect of this assumption is an increase of ethane production by a factor of 3 due to scavenging of $\mathrm{H}$ atoms and smaller loss of $\mathrm{CH}_{3}$ in (R20) $\mathrm{CH}_{3}+\mathrm{H}$. Hydrogen atoms do not form $\mathrm{H}_{2}$, reducing the $\mathrm{H}_{2}$ densities and total hydrogen escape flux by a factor of 2 . Reaction (R82) $\mathrm{N}_{2}^{+}+\mathrm{H}_{2}$ is the main loss mechanism for $\mathrm{N}_{2}^{+}$; therefore $\mathrm{N}_{2}^{+}$and production of $\mathrm{C}^{+}$are larger due to the reduction of $\mathrm{H}_{2}$ in this model. The peak electron density is larger than the measured value by a factor of 1.5 , and a reduction in $k_{84,95}$ may be applied to fit the measured electron density.

The main properties of our model are rather stable even under the extreme conditions of models 1,2 , and 3 . Now we consider variations of the model results arising from changes in the assumed CO mixing ratio. These changes are compensated by a proper choice of $k_{84,95}$ to fit the measured peak electron density. Model 4 has $f_{\mathrm{CO}}=10^{-4}$ and $k_{84,95}=8 \times 10^{-11}$ $\mathrm{cm}^{3} / \mathrm{s}$ (Figure 6), and model 5 is for $10^{-3}$ and $2 \times 10^{-11} \mathrm{~cm}^{3} / \mathrm{s}$, respectively. The effects of the $\mathrm{CO}$ variation (by a factor of 10) are nonlinear: variations of the CO density at $300 \mathrm{~km}$ are a factor of 24 , and variations of $\mathrm{C}$ and $\mathrm{O}$ densities above 250 $\mathrm{km}$ and of their escape fluxes are a factor of 5 . The product $f_{\mathrm{CO}} k_{84,95}$ is not constant.

Comparing model 4 with our basic model, we see the expected reductions in the densities of $\mathrm{CO}, \mathrm{C}$, and $\mathrm{O}$ (neutrals) and of $\mathrm{CO}^{+}$and $\mathrm{NO}^{+}$(ions). $\mathrm{N}^{+}, \mathrm{N}_{2}^{+}, \mathrm{N}_{2} \mathrm{H}^{+}$, and $\mathrm{H}^{+}$ densities are rather insensitive to the $\mathrm{CO}$ change.

Model 6 is our model adjusted to the conditions of the model of LYA93: solar (without magnetospheric electrons) ionization, the $\mathrm{CO}$ mixing ratio is $10^{-4}$, the ion escape is thermal $\left(v_{i}=10 \mathrm{~cm} / \mathrm{s}\right)$, the charge-exchange rate coefficient is $10^{-10} \mathrm{~cm}^{3} / \mathrm{s}$, the $\mathrm{CH}+\mathrm{N}_{2}$ cycle is absent, and the radiative recombination coefficients are $5 \times 10^{-12} \mathrm{~cm}^{3} / \mathrm{s}$. Despite differences in other reactions and their rate coefficients and in the aerosol properties (see section 4 ) between model 6 and LYA93, the results are rather similar. This confirms the idea of the stability of the model relative to variations in input data, except for a few (the magnetospheric electron energy input, $f_{\mathrm{CO}}, k_{84,95}, v_{\mathrm{i}}$ ).

Model 7 is adjusted to that of SS95: the magnetospheric electron energy input is $1.4 \times 10^{8} \mathrm{~W}$, the $\mathrm{CO}$ mixing ratio is $2.5 \times 10^{-4}, k_{84.95}=10^{-11} \mathrm{~cm}^{3} / \mathrm{s}, v_{i}=10 \mathrm{~cm} / \mathrm{s}$ (we do not know their $v_{i}$ ). Again the electron density profile in model 7 is

Table 9. Main Production and Loss of $\mathrm{C}^{+}$

\begin{tabular}{ll}
\hline Process & Column Rate \\
\hline $\mathrm{N}_{2}^{+}+\mathrm{C} \rightarrow \mathrm{C}^{+}+\mathrm{N}_{2}$ & 1.64 \\
$\mathrm{CO}^{+}+\mathrm{C} \rightarrow \mathrm{C}^{+}+\mathrm{CO}$ & 0.19 \\
$\mathrm{C}+h v \rightarrow \mathrm{C}^{+}+e$ & 0.07 \\
Total production & 1.90 \\
& \\
$\mathrm{C}^{+}+e \rightarrow \mathrm{C}+h v$ & 0.23 \\
$\mathrm{C}^{+}+\mathrm{CH}_{4} \rightarrow$ products & 0.37 \\
$\mathrm{C}^{+}+{\mathrm{HCN} \rightarrow \mathrm{C}_{2} \mathrm{~N}^{+}+\mathrm{H}}_{\text {Escape }}$ & 0.17 \\
Total loss & 1.14 \\
\hline
\end{tabular}

Values are in units of $10^{6} \mathrm{~cm}^{-2} \mathrm{~s}^{-1}$. 
Table 10. Models of Triton's Atmosphere and Ionosphere

\begin{tabular}{|c|c|c|c|c|c|c|c|c|c|}
\hline Value & Measured & Basic & $1 *$ & 27 & $3^{7}$ & 4 & 5 & $6^{8}$ & 79 \\
\hline$f_{C O} \times 10^{-4}$ & - & $\overline{3}$ & 3 & 3 & 3 & $\overline{1}$ & 10 & 1 & 2.5 \\
\hline$k\left(\mathrm{~N}_{2}{ }^{+}, \mathrm{CO}^{+}+\mathrm{C}\right), \times 10^{-11}$ & - & 4 & 4 & 4 & 4 & 8 & 2 & 10 & 1 \\
\hline$v_{i}, \mathrm{~cm} / \mathrm{s}$ & - & 150 & 150 & 150 & 150 & 150 & 150 & 10 & 10 \\
\hline$h_{\max }, \mathrm{km}$ & 340 & 320 & 320 & 300 & 300 & 290 & 330 & 280 & 290 \\
\hline$e_{\max }, \times 10^{4} \mathrm{~cm}^{-3}$ & $3.5 \pm 1$ & 3.5 & 3.6 & 4.25 & 5.1 & 3.6 & 3.0 & 3.3 & 3.4 \\
\hline$e_{700 \mathrm{~km}}, \times 10^{4} \mathrm{~cm}^{-3}$ & $0.55 \pm 0.1$ & 0.76 & 0.75 & 0.78 & 1.01 & 0.77 & 0.56 & 1.00 & 1.52 \\
\hline$\left[\mathrm{N}^{+}\right]_{700 \mathrm{~km}}, \times 10^{4} \mathrm{~cm}^{-3}$ & - & 0.34 & 0.34 & 0.33 & 0.57 & 0.45 & 0.13 & 0.09 & 0.71 \\
\hline$[\mathrm{N}]_{200 \mathrm{~km}}, \times 10^{8} \mathrm{~cm}^{-3}$ & $5 \pm 2.5$ & 5.7 & 5.7 & 5.9 & 5.9 & 6.5 & 4.9 & 2.5 & 7.5 \\
\hline$[\mathrm{N}]_{400 \mathrm{~km}} \times 10^{7} \mathrm{~cm}^{-3}$ & $10 \pm 3$ & 7.2 & 7.2 & 7.5 & 7.5 & 7.7 & 6.5 & 3.1 & 9.6 \\
\hline$[\mathrm{CO}]_{300 \mathrm{kmII}}, \times 10^{6} \mathrm{~cm}^{-3}$ & - & 1.1 & 1.1 & 1.0 & 0.7 & 0.3 & 6.5 & 0.6 & 0.7 \\
\hline$[\mathrm{C}]_{300 \mathrm{kan},} \times 10^{6} \mathrm{~cm}^{-3}$ & - & 3.9 & 3.8 & 4.3 & 4.4 & 1.4 & 7.1 & 0.9 & 4.0 \\
\hline$\Phi_{N}, \times 10^{24} \mathrm{~s}^{-1}$ & $10 \pm 3$ & 7.7 & 7.7 & 8.0 & 8.2 & 8.6 & 6.8 & 3.2 & 10.0 \\
\hline$\Phi_{\mathrm{H} 2}, \times 10^{25} \mathrm{~s}^{-1}$ & - & 4.5 & 4.6 & 4.8 & 2.1 & 4.4 & 4.8 & 5.4 & 4.2 \\
\hline$\Phi_{\mathrm{H}}, \times 10^{25} \mathrm{~s}^{-1}$ & - & 2.4 & 2.4 & 2.2 & 1.6 & 2.7 & 1.8 & 0.7 & 3.3 \\
\hline$\Phi_{0}, \times 10^{22} \mathrm{~s}^{-1}$ & - & 4.4 & 4.4 & 5.1 & 4.8 & 1.7 & 8.4 & 0.8 & 4.3 \\
\hline$\Phi_{\mathrm{C}}, \times 10^{-4} \mathrm{~s}^{-1}$ & - & 1.1 & 1.1 & 1.2 & 1.2 & 0.4 & 2.0 & 0.24 & 1.1 \\
\hline$\Phi_{\mathrm{C}+}, \times 10^{23} \mathrm{~s}^{-1}$ & - & 2.6 & 2.6 & 2.8 & 2.8 & 2.0 & 2.7 & 0.4 & 0.4 \\
\hline$S_{\mathrm{cll}}, \mathrm{g} \mathrm{cm}^{-2}$ b.y. & - & 1.3 & 1.5 & 3.3 & 0.7 & 1.2 & 0.8 & 1.3 & 1.4 \\
\hline$S_{(21 / 4}, g c^{-2}$ b.y. ${ }^{-1}$ & - & 135 & 164 & 133 & 155 & 137 & 134 & 166 & 166 \\
\hline$S_{(2) 16}, \mathrm{~g} \mathrm{~cm}^{-2}$ b.y..$^{-1}$ & - & 28 & 22 & 28 & 81 & 29 & 27 & 22 & 22 \\
\hline$S_{\mathrm{HCN}}, \mathrm{g} \mathrm{cm}^{-2}$ b.y. & - & 29 & 0.57 & 36 & 10 & 32 & 28 & 3 & 3 \\
\hline
\end{tabular}

\footnotetext{
Here, $f_{\mathrm{CO}}$ is the $\mathrm{CO}$ mixing ratio, $v_{i}$ is the ion escape velocity, $h_{\max }$ and $e_{\max }$ are the altitude and electron density at the ionospheric peak, $\Phi_{i}$ and $S_{i}$ are the total escape and sedimentation fluxes of $i$ species.

* Basic model without $(\mathrm{R} 60) \mathrm{HCN}_{2}+\mathrm{H}$.

† Basic model without (R25) $\mathrm{C}+\mathrm{N}_{2}+\mathrm{M}$.

* Basic model with condensation and scavenging of all species except $\mathrm{N}_{2}, \mathrm{CH}_{4}, \mathrm{CO}$, and $\mathrm{H}_{2}$.

Analog of the solar model of LYA: (R60) $\mathrm{HCN}_{2}+\mathrm{H}$ is neglected, radiative recombination coefficients are $5 \times 10^{-12}$ $\mathrm{cm}^{3} / \mathrm{s}$.

Analog to $S S$ with $P=1.4 \times 10^{8} \mathrm{~W}$ and without $(\mathrm{R} 60)$.
}

rather similar to that of SS95 (we do not have other results of SS95).

Of all our models, only model 6 fails to reproduce the measured profile of atomic nitrogen. This is the solar model (without precipitation of magnetospheric electrons). Therefore the main conclusions of the model comparison are that (1) magnetospheric electron energy input of about $10^{8} \mathrm{~W}$, i.e., approximately twice the solar EUV input, is needed to reproduce the measured $\mathrm{N}$ densities, and (2) it is impossible to establish firm constraints to the $\mathrm{CO}$ mixing ratio by modeling the atmosphere and the ionosphere with the unknown rate coefficient $k_{84}$. The plausible range $10^{-11}-10^{-10}$ $\mathrm{cm}^{3 / 3}$ for $k_{84}$ requires the $\mathrm{CO}$ mixing ratio in the range $10^{-4}$ $10^{-3}$. Measurements of the $\mathrm{CO}$ mixing ratio in Triton's atmosphere, and laboratory measurements of the charge exchange between $\mathrm{N}_{2}{ }^{+}$and $\mathrm{C}$ are of great importance to Triton's photochemistry.

\section{Conclusions}

We have considered the phorochemistry of 32 neutral and 21 ion species in Triton's atmosphere. The model shows that three parent species $\mathrm{N}_{2}, \mathrm{CH}_{4}$, and $\mathrm{CO}$ (with a mixing ratio of $3 \times 10^{-4}$ in our basic model) sublime from the ice with rates of
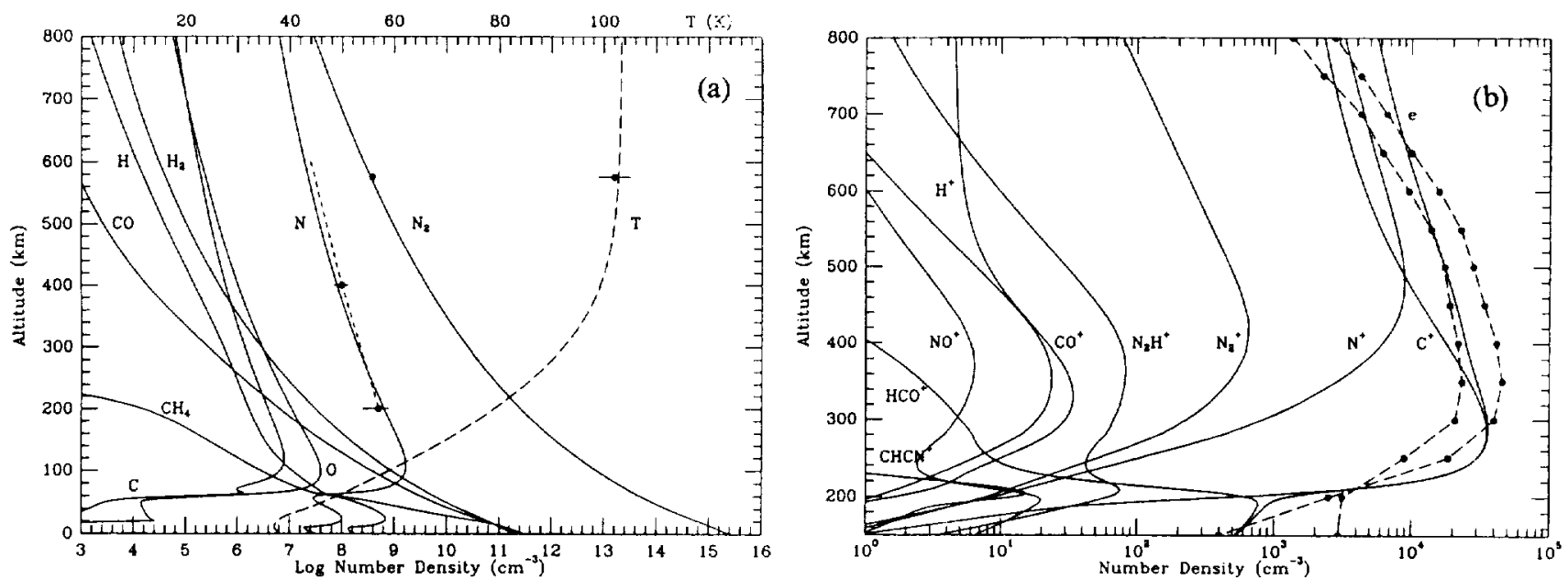

Figure 6. Model 4 with the $\mathrm{CO}$ mixing ratio of $10^{-4}$ and $k\left(\mathrm{~N}_{2}^{+}+\mathrm{C}\right)=8 \times 10^{-11} \mathrm{~cm}^{3} / \mathrm{s}$ : basic (a) neutral and (b) ion species. 
40, 208, and $0.3 \mathrm{~g} / \mathrm{cm}^{2} / \mathrm{b} . y$. , respectively. Photolysis of methane by the solar and the interstellar background Lymanalpha radiation drives the chemistry below $50 \mathrm{~km}$ and produces hydrocarbons $\mathrm{C}_{2} \mathrm{H}_{4}, \mathrm{C}_{2} \mathrm{H}_{6}$, and $\mathrm{C}_{2} \mathrm{H}_{2}$. These hydrocarbons form the haze particles and precipitate with rates of 135,28 , and $1.3 \mathrm{~g} / \mathrm{cm}^{2} /$ b.y., respectively. The $\mathrm{CH}+\mathrm{N}_{2}$ cycle we introduced increases the production of $\mathrm{HCN}$ by more than an order of magnitude to a value of $29 \mathrm{~g} / \mathrm{cm}^{2} / \mathrm{b}$.y., and results in the indirect photolysis of $\mathrm{N}_{2}$. Using the method proposed by Strobel et al. [1990a], we find from the measured methane profiles the eddy diffusion coefficient $K=4 \times 10^{3}$ $\mathrm{cm}^{2} / \mathrm{s}$ above the tropopause and a methane number density of $(3.1 \pm 0.8) \times 10^{11} \mathrm{~cm}^{-3}$ near the surface. Solar EUV radiation $(\lambda<1000 \AA)$ and precipitation of magnetospheric electrons are responsible for chemistry above $200 \mathrm{~km}$. We assume a magnetospheric electron energy input of $10^{8} \mathrm{~W}$ based on the thermal balance calculations. $\mathrm{N}, \mathrm{H}_{2}, \mathrm{H}, \mathrm{O}$, and $\mathrm{C}$ are the most abundant photochemical species, with total escape rates of $7.7 \times 10^{24} \mathrm{~s}^{-1}, 4.5 \times 10^{25} \mathrm{~s}^{-1}, 2.4 \times 10^{25} \mathrm{~s}^{-1}, 4.4 \times 10^{22} \mathrm{~s}^{-1}$, and $1.1 \times 10^{24} \mathrm{~s}^{-1}$, respectively. The chemistry of a very interesting intermediate region at $50-200 \mathrm{~km}$ is driven mostly by the atomic species, which are transported to this region from the atmosphere above and below it. The ionosphere consists of the $E$ region at $150-240 \mathrm{~km}$ and of the $F$ region above 240 $\mathrm{km}$. A major ion of the $E$ region is $\mathrm{HCO}^{+} . \mathrm{C}^{+}$dominates in the $F$ region and forms the peak at $320 \mathrm{~km}$. The ionosphere above $500 \mathrm{~km}$ includes almost equal densities of $\mathrm{C}^{+}$and $\mathrm{N}^{+}$ ions. The calculated profiles of atomic nitrogen and electron densities agree with the measurements.

Some other models with some reactions removed or changed, with changed properties of the haze particles (from chemically passive to active at a maximum rate), etc., were developed. These models show that some of these variations are relatively unimportant for the basic structure and composition of the atmosphere and provide some local changes in some species. However, there are four basic unknown values which have strong impacts on the composition of the atmosphere and ionosphere. These values and their plausible ranges are the $\mathrm{CO}$ mixing ratio $f_{\mathrm{CO}}=10^{-4}-10^{-3}$, the magnetospheric electron energy input $(1 \pm 0.5) \times 10^{8} \mathrm{~W}$, the rate coefficient of charge-exchange reaction $\mathrm{N}_{2}^{+}+\mathrm{C} k=10^{-11}$. $10^{-10} \mathrm{~cm}^{3} / \mathrm{s}$, and the ion escape velocity $v_{i} \approx 150 \mathrm{~cm} / \mathrm{s}$. Various combinations of these values allow us to construct models which fit the measured $\mathrm{N}$ and electron densities. Therefore measurement of $\mathrm{CO}$ in Triton's atmosphere (which we hope can be made by ground-based spectroscopy) and laboratory study of the $\mathrm{N}_{2}^{+}+\mathrm{C}$ reaction are very important. Modeling shows that the measured profile of atomic nitrogen cannot be reproduced without a substantial magnetospheric electron energy input, which should exceed the solar EUV input by a factor of 2-3. If it does, then the ionopause is rather close to the exobase (SS95), and the ion escape velocity is much larger than that for thermal escape. This increases requirements on the $\mathrm{N}_{2}^{+}+\mathrm{C}$ reaction.

Some results discussed here may be used for modeling of the $\mathrm{N}_{2}-\mathrm{CH}_{4}$ atmospheres of Titan and Pluto while others may not. For example, formation of $\mathrm{HCN}$ by the $\mathrm{CH}-\mathrm{N}_{2}$ mechanism is important only in atmospheres with a very low $\mathrm{CH}_{4}$ mole fraction, and the yield of $\mathrm{HCN}$ in methane photolysis may be given as

$$
\gamma=\left(1+2 t_{\mathrm{CH} 4}^{2} \frac{k_{2 \mathrm{~B}}}{k_{24}} \sigma_{\mathrm{CH} 4} H_{\mathrm{CH} 4}\right)^{-1}
$$

where $\sigma_{\mathrm{CH} 4}=1.8 \times 10^{-17} \mathrm{~cm}^{2}$ is the cross section at $1216 \AA$. This yield is negligible $\left(10^{-8}\right)$ on Titan, where $\mathrm{f}_{\mathrm{CH} 4} \approx 0.08$ at the level of methane photolysis.

Photochemical production of $\mathrm{CO}_{2}$ is too low to explain the observed ratio of $10^{-3}$ in the ice [Cruikshank et al., 1993], while the production of $\mathrm{C}_{2} \mathrm{H}_{x}$ and $\mathrm{HCN}$ is too large to be missed in the observations. A reasonable explanation is decomposition of these species in the ice by the solar radiation $\lambda>1400 \AA$ [Allen et al., 1994]. The atmosphere is transparent for this radiation, and other species may form, resulting in coloration of the ice [Thompson and Sagan, 1990]. Bohn et al. [1994] have suggested that formation of the highly reactive molecule $\mathrm{CH}_{2} \mathrm{~N}_{2}$ may synthesize larger alkanes from $\mathrm{CH}_{4}$ and $\mathrm{C}_{2} \mathrm{H}_{6}$, driving organics in the surface ices toward saturation (i.e., to reduce multiple $\mathrm{C}-\mathrm{C}$ bonds).

Acknowledgments. This work was supported in part by the NASA Planetary Astronomy Program through a consortium research interchange between NASA Ames Research Center and the University of Califomia, Berkeley, and was finished when one of us (V.K.) held a National Research Council-NASA/GSFC Senior Research Associateship.

\section{References}

Allen, C. W., Astrophysical Quantities, Athlone, London, 1973.

Allen, M., R. Dissly, and V. Anicich, Photolysis of ethylene ice on Triton's surface, Bull. Am. Astron. Soc., 26, 1177, 1994.

Anicich, V. G., Evaluated bimolecular ion-molecule gas phase kinetics of positive ions for use in modeling planetary atmospheres, cometary comae, and interstellar clouds, J. Plys. Chem. Ref. Data, 22, 1469-1569, 1993.

Atreya, S. K., Atmospheres and lonospheres of the Outer Planets and Their Satellites, Springer-Verlag, New York, 1986.

Banks, P. M., and G. Kockarts, Aeronomy, Academic, San Diego, Calif., 1973.

Bauer, W., K. H. Becker, and R. Menser, Laser-induced fluorescence studies on $\mathrm{C}_{2} \mathrm{O}$ and $\mathrm{CH}$ radicals, Ber. Bunsenges. Phys. Chem, 89, 340, 1985.

Baulch, D. L., et al., Evaluated kinetic data for combustion modelling, J. Phys. Chem. Ref. Data, 21, 411-734, 1992.

Berman, M. R., and M. C. Lin, Kinetics and mechanism of the $\mathrm{CH}$ $+\mathrm{N}_{2}$ reaction. Temperature- and pressure-dependence studies and transition-state-theory analysis, J. Phys. Chem., 87, 3933, 1983a.

Berman, M. R., and M. C. Lin, Kinetics and mechanisms of the reactions of $\mathrm{CH}$ with $\mathrm{CH}_{4}, \mathrm{C}_{2} \mathrm{H}_{6}$ and $\mathrm{n}-\mathrm{C}_{4} \mathrm{H}_{10}$, Chem. Phys., 82, $435,1983 b$.

Berman, M.R., and M. C. Lin, Kinetics and mechanism of the reactons of $\mathrm{CH}$ and $\mathrm{CD}$ with $\mathrm{H}_{2}$ and $\mathrm{D}_{2}, J$. Chem. Phys., 81, $5743,1984$.

Bohn, R. B., S. A. Sandford, L. J. Allamandola, and D. P. Cruikshank, Infrared spectroscopy of Triton and Pluto ice analogs: The case for saturated hydrocarbons, Icarus, 111, 151, 1994.

Braun, W., A. M. Bass, D. D. Davis, and J. D. Simmons, Flash photolysis of carbon suboxide: absolute rate constants for reactions of $\mathrm{C}\left({ }^{3} P\right)$ and $\mathrm{C}\left({ }^{1} D\right)$ with $\mathrm{H}, \mathrm{N}, \mathrm{CO}, \mathrm{NO}, \mathrm{O}_{2}$ and $\mathrm{CH}_{4}$, Proc. $R$. Soc. London A, 312, 417, 1969.

Broadfoot, A. L., et al., Ultraviolet spectrometer observations of Neptune and Triton, Science, 246, 1459, 1989.

Brown, G. N., and W. T. Ziegler, Vapor pressure and heats of vaporization and sublimation of liquids and solids of interest of cryogenics below 1-atm pressure, Adv. Cryog. Eng., 25, 662, 1979.

Brown, R. L., A measurement of the rate of the reaction $\mathrm{N}+\mathrm{H}+$ $\mathrm{M} \rightarrow \mathrm{NH}+\mathrm{M}$, Int. J. Chem. Kinet., 5, 663, 1973.

Campbell, I. M., and C. N. Gray, Rate constants for $\mathrm{O}\left({ }^{3} P\right)$ recombination and association with $\mathrm{N}\left({ }^{4} S\right)$, Chem. Phys. Lett., 18, 607, 1973.

Campbell, I. M., and B. A. Thrush, The recombination of nitrogen atoms and the nitrogen afterglow, Proc. $R$ Soc. London A, 296, 201-211, 1967. 
Cantu, A. M., M. Mazzoni, M. Pettini, and G. P. Tozzi, Photoionization spectrum of the ${ }^{3} \mathrm{P}$ ground state of neutral carbon, Phys. Rev. A, 23, 1223, 1981.

Chamberlain, J. W., and D. M. Hunten, Theory of Planetary Atmospheres, Academic, San Diego, Calif., 1987.

Cohen, N., and K. R. Westberg, Chemical kinetic data sheets for high-temperature reactions, II, J. Phys. Chem. Ref. Data, 20, $1211,1991$.

Comes, F. J., and A. F. Elzer, Photoionisationsuntersichungen an Atomstrahlen, III, Der Ionisierungsquerschnitt des atomaren Stickstoffs, Z Naturforsch. A, 23, 133, 1968.

Conrath, B., et al., Infrared observations of the Neptunian system, Science, 246, 1454, 1989.

Cruikshank, D. P., and J. Apt, Methane on Triton: physical state and distribution, Icarus, 58, 306, 1984.

Cruikshank, D. P., R. H. Brown, and R. N. Clark, Nitrogen on Triton, Icarus, 58, 293, 1984.

Cruikshank, D. P., T. L. Roush, T. C. Owen, T. R. Geballe, C. de Bergh, B. Schmitt, R. H. Brown, and M. J. Bartholomew, Ices on the surface of Triton, Science, 26I, 742-745, 1993.

Dalgarno, A., J. F. Babb, and Y. Sun, Radiative association in planetary atmospheres, Planet. Space Sci., 40, 243, 1992.

Dorthe, G., P. Caubet, T. Vias, B. Barrere, and J. Marchais, Fast flow studies of atomic carbon kinetics at room temperature, $J$. Phys. Chem., 95, 5109-5116, 1991.

Fairbaim, A. R., The dissociation of carbon monoxide, Proc. $R$. Soc. London A, 312, 207-227, 1969.

Fehsenfeld, F. C., and E. E. Ferguson, Thermal energy reaction rate constants for $\mathrm{H}^{+}$and $\mathrm{CO}^{+}$with $\mathrm{O}$ and NO, J. Chem Phys., 56, 3066-3070, 1972

Fox, J. L., and J. H. Black, Photodissociation of $\mathrm{CO}$ in the thermosphere of Venus, Geophys. Res. Lett., 16, 291, 1989.

Fox, J. L., and G. A. Victor, Electron energy deposition in $\mathrm{N}_{2}$ gas, Planet. Space Sci., 36, 329, 1988.

Frost, M. J., P. Sharkey, and I. W. M. Smith, Reaction between OH (OD) radicals and $\mathrm{CO}$ at temperatures down to $80 \mathrm{~K}$ : Experiment and theory, J. Phys. Chem., 97, 12,254-12,259, 1993.

Haider, N., and D. Husain, The collisional behaviour of ground state atomic carbon, $\mathrm{C}\left(2 p^{2}\left({ }^{3} P_{j}\right)\right)$, with ethylene and acetylene investigated by time-resolved atomic resonance absorption spectroscopy in the vacuum ultraviolet, $J$. Photochem. Photobiol. A, 70, $119-$ $124,1993$.

Harding, L. B., R. Guadagnini, and G. C. Schatz, Theoretical studies of the reactions $\mathrm{H}+\mathrm{CH}=\mathrm{C}+\mathrm{H}_{2}$ and $\mathrm{C}+\mathrm{H}_{2}=\mathrm{CH}_{2}$ using an ab initio global ground-state potential surface for $\mathrm{CH}_{2}, J$. Phys. Chem., 97, 5472-5481, 1993.

Herbert, F., and B. R. Sandel, $\mathrm{CH}_{4}$ and haze in Triton's lower atmosphere, J. Geophys. Res., 96, 19,241, 1991.

Howard, M. J., and I. W. M. Smith, Direct rate measurements on the reactions $\mathrm{N}+\mathrm{OH} \rightarrow \mathrm{NO}+\mathrm{H}$ and $\mathrm{O}+\mathrm{OH} \rightarrow \mathrm{O}_{2}+\mathrm{H}$ from 250 to $515 \mathrm{~K}, J$. Chem. Soc. Faradory Trans. 2, 77, 997, 1981.

Husain, D., and L. J. Kirsch, Reactions of atomic carbon $C\left(2^{3} \mathrm{P}_{\mathrm{j}}\right)$ by kinetic absorption spectroscopy in the vacuum ultraviolet, Trans. Faraday Soc., 67, 2025, 1971.

Husain, D., and A. N. Young, Kinetic investigation of ground state carbon atoms, $\mathrm{C}\left(2^{3} P\right)$, J. Chem. Soc. Faraday Trans. 2, 7I, 525, 1975.

Kirby, K., E. R. Constantinides, S. Babeu, M. Oppenheimer, and G. A. Victor, Photoionization and photoabsorption cross sections of $\mathrm{He}, \mathrm{O}, \mathrm{N}_{2}$ and $\mathrm{O}_{2}$ for aeronomic calculations, Atomic Data Nucl. Data Table, 23, 63, 1979.

Kley, D., N. Washida, and W. Groth, Mechanism of $\mathrm{CN}^{*}$ production in flames of active nitrogen with cyanogen, Ber. Bunsenges. Phys. Chem., 78, 205, 1974.

Krasnopolsky, V. A., Photochemistry of the Martian atmosphere (mean conditions), Icarus, 101, 313-332, 1993a.

Krasnopolsky, V. A., On the haze model for Triton, J. Geophys. Res., 98, 17,123-17,124, 1993b.

Krasnopolsky, V. A., B. R. Sandel, and F. Herbert, Properties of haze in the atmosphere of Triton, J. Geophys. Res., 97, 11,695$11,700,1992$.

Krasnopolsky, V. A., B. R. Sandel, F. Herbert, and R. J. Vervack, Temperature, $\mathrm{N}_{2}$, and $\mathrm{N}$ density profiles of Triton's atmosphere: Observations and model, J. Geophys. Res., 98, 3065-3078, 1993.
Krimigis, S. M., et al., Hot plasma and energetic particles in Neptune's magnetosphere, Science, 246, 1483, 1989.

Laufer, A. H., E. P. Gandner, T. L. Kwok, and Y. L. Yung, Computations and estimates of rate coefficients for hydrocarbon reactions of interest to the atmospheres of the outer solar system, Icarus, 56, 560-567, 1983.

Lean, J., Variations in the Sun's radiative output, Rev. Geophys., 29, 505, 1991.

Lyons, J. R., Y. L. Yung, and M. Allen, Solar control of the upper atmosphere of Triton, Science, 246, 1483, 1992.

Majeed, T., J. C. McConnell, D. F. Strobel, and M. E. Summers, The ionosphere of Triton, Geophys. Res. Lett., 17, 1721-1724, 1990.

Mallard, W. G., F. Westley, J. T. Herron, and R. F. Hampson, NIST Chemical Kinetics Database, version 6.0, Nat. Inst. of Standands and Technol., Gaithersburg, Md., 1994.

Marston, G., F. L. Nesbitt, D. F. Nava, W. A. Payne, and L. J. Stief, Temperature dependence of the reaction of nitrogen atoms with methyl radicals, J. Phys. Chem, 93, 5769, 1989.

Messing, I., S. V. Filseth, C. M. Sadowski, and T. Carrington, Absolute rate constants for the reactions of $\mathrm{CH}$ with $\mathrm{O}$ and $\mathrm{N}$ atoms, J. Chem. Phys., 74, 3874, 1981.

Miller, J. A., M. C. Branch, W. J. McLean, D. W. Chandler, M. D. Smooke, and R. J. Kee, The conversion of $\mathrm{HCN}$ to $\mathrm{NO}$ and $\mathrm{N}_{2}$ in the $\mathrm{H}_{2}-\mathrm{O}_{2}-\mathrm{HCN}-\mathrm{Ar}$ flames at low pressure, Symp. Imt. Combust. Proc., 20, 673, 1985.

Mitchell, J. B. A., The dissociative recombination of molecular ions, Phys. Rep., 186, 215, 1990.

Monks, P. S., P. N. Romani, F. L. Nesbitt, M. Scanlon, and L. J. Stief, The kinetics of the formation of nitrile compounds in the atmospheres of Titan and Neptune, J. Geophys. Res., 98, 17, 115, 1993.

Mordaunt, D. H., I. R. Lambert, G. P. Morley, M. N. R. Amold, R. N. Dixon, C. M. Western, L. Schnieder, and K. H. Welge, Primary product channels in the photodissociation of methane at $121.6 \mathrm{~nm}, J$. Chem. Phys., 98, 2054-2065, 1993.

Morley, C., The mechanism of NO formation from nitrogen compounds in hydrogen flames studied by laser fluorescence, Symp. Int. Combust. Proc., 18, 23, 1981.

Okabe, H., Photochemistry of Small Molecules, John Wiley, New York, 1978.

Okabe, H., Photochemistry of acetylene at $1849 \AA$ A, J. Chem. Phys., 78, 1312-1317, 1983.

Pollack, J. B., J. M. Schwartz, and K. Rages, Scatterers in Triton's atmosphere: Implications for the seasonal volatile cycle, Science, $250,440,1990$.

Prasad, S. S., and W. T. Huntress, A model for gas phase chemistry in interstellar clouds, I, The basic model, library of chemical reactions, and chemistry among $\mathrm{C}, \mathrm{N}$, and $\mathrm{O}$ compounds, Astrophys. J. Suppl. Ser., 43, 1, 1980.

Rages, K., and J. B. Pollack, Voyager imaging of Triton's clouds and hazes, Icarus, 99, 289, 1992.

Sayah, N., X. Li, J. F. Caballero, and W. M. Jackson, Laser induced fluorescence studies of $\mathrm{CN}$ reactions with alkanes, alkenes and substituted aliphatic species, J. Photochem. Photobiol. A, 45, 177 , 1988.

Sims, I. R., J.-L. Queffelec, D. Travers, B. R. Rowe, L. B. Herbert, J. Karthauser, and I. W. M. Smith, Rate constants for the reactions of $\mathrm{CN}$ with hydrocarbons at low and ultra-low temperatures, Chem. Phys. Lett., 211, 461-468, 1993.

Slack, M. W., Kinetics and thermodynamics of the $\mathrm{CN}$ molecule, III, Shock tube measurement of $\mathrm{CN}$ dissociation rates, $J$. Chem. Phys., 64, 228, 1976.

Stark, G., P. L. Smith, K. P. Huber, K. Yoshino, M. H. Stevens, and K. Ito, Absorption band oscillator strengths of $\mathrm{N}_{2}$ transitions between 95.8 and $99.4 \mathrm{~nm}, J$. Chem. Phys., 97, 4809, 1992.

Stevens, M. H., D. F. Strobel, and M. E. Summers, On the thermal structure of Triton's thermosphere, Geophys. Res. Lett., 19, 669$672,1992$.

Strobel, D. F., and M. E. Summers, Triton's upper atmosphere and ionosphere, Neptune and Triton, edited by D. P. Cruikshank, Univ. of Ariz. Press, Tucson, in press, 1995.

Strobel, D. F., M. E. Summers, F. Herbert, and B. R. Sandel, The 
photochemistry of methane in the atmosphere of Triton, Geophys. Res. Lett., 17, 1729-1732, 1990a.

Strobel, D. F., A. F. Cheng, M. E. Summers, and D. J. Strickland, Magnetospheric interaction with Triton's ionosphere, Geophys. Res. Lett., 17, 1661-1664, 1990b.

Summers, M. E., and D. F. Strobel, Triton's atmosphere: A source of $\mathrm{N}$ and $\mathrm{H}$ for Neptune's magnetosphere, Geophys. Res. Lett., 18, 2309-2312, 1991.

Thompson, W. R., and C. Sagan, Color and chemistry on Triton, Science, 250, 415, 1990.

Torr, M. R., and D. G. Torr, Ionization frequencies for solar cycle 21: revised, J. Geophys. Res., 90, 6675, 1985.

Torr, M. R., D. G. Torr, and R. A. Ong, lonization frequencies for major thermospheric constituents as a function of solar cycle 21 , Geophys. Res. Lett., 6, 771-774, 1979.

Tryka, K. A., R. H. Brown, D. P. Cruikshank, T. C. Owen, T. R. Geballe, and C. DeBergh, Temperature of nitrogen ice on Pluto and its implications for flux measurements, Icarus 112, 513-527, 1994.

Tsang, W., and R. F. Hampson, Chemical kinetic data base for combustion chemistry, Part I, Methane and related compounds, J. Phys. Chem. Ref. Data, 15, 1087, 1986.

Tyler, G. L., et al., Voyager radio science observations of Neptune and Triton, Science, 246, 1466, 1989.
Whyte, A.R., and L. F. Phillips, Rate of reaction of $\mathrm{N}$ with $\mathrm{CN}(\mathrm{v}=$ 0, 1), Chem Phys. Lett., 98, 590, 1983.

Yelle, R. V., J. L. Lunine, and D. M. Hunten, Energy balance and plume dynamics in Triton's lower atmosphere, Icarus, 89, 347, 1991.

Yu, T., D. L. Yang, and M. C. Lin, Kinetics of $\mathrm{CN}$ radical reactions with formaldehyde and 1,3,5-trioxane, Int. J. Chem . Kinet., 25, 1053-1064, 1993.

Yung, Y. L., and J. R. Lyons, Triton: Topside ionosphere and nitrogen escape, Geophys. Res. Lett., 17, 1717, 1990.

Yung, Y. L., M. Allen, and J. P. Pinto, Photochemistry of the atmosphere of Titan: Comparison between model and observations, Astrophys. J. Suppl. Ser. 55, 465, 1984.

Zipf, E. C., and R. W. McLaughlin, On the dissociation of nitrogen by electron impact and by EUV photoabsorption, Planet. Space Sci., 26, 449, 1978.

D. P. Cruikshank, Astrophysics Branch, NASA Ames Reseanch Center, Moffett Field, CA 94035.

V. A. Krasnopolsky, NRC/NASA Goddard Space Flight Center, Code 693, Greenbelt, MD 20771.

(Received February 16, 1995; revised June 19, 1995; accepted June 20,1995.) 